\title{
How open lists undermine the electoral support of cohesive parties *
}

\author{
Thomas Bräuninger $^{\dagger} \quad$ Thomas Däubler ${ }^{\ddagger} \quad$ Robert Huber $\S$ \\ Lukas Rudolph
}

\begin{abstract}
How does ballot structure affect party choice? We argue that open lists undermine the electoral support of cohesive parties, to the benefit of internally divided parties. This effect is mainly due to indifferent voters close to the midpoint of the two parties' positions on a contested policy issue. We conduct a survey-embedded experiment in the aftermath of the European migrant crisis, presenting German voters real parties with fictitious politicians. A crossover design varies ballot type and exposure to candidate positions on immigration. We find that the internally divided CDU/CSU gains votes at the expense of the cohesive AfD when open lists are used and candidate positions are known. This effect is much stronger than among participants indifferent between the AfD and any other competitor. Overall, our analysis establishes conditions under which ballot structure can affect electoral performance of parties in general, and that of the populist right in particular.
\end{abstract}

Keywords: electoral systems, open-list PR, party heterogeneity, European migrant crisis, survey experiment, populism

${ }^{*}$ We would like to thank Liam F. Beiser-McGrath, Jack Blumenau, Gracia Brückmann, Andrew Eggers, Dominik Hangartner, Dennis Kolcava, Denise Laroze, and Michael L. Wicki for very helpful feedback on previous manuscript drafts. We as well thank audiences at ETH Zurich and the EPSA 2019 Annual Conference for thoughtful comments. Thomas Däubler acknowledges funding from the German Research Foundation, grant DA 1692/1-1.

†University of Mannheim, thomas.braeuninger@uni-mannheim.de

$\ddagger$ University College Dublin, thomas.daubler@ucd.ie

$\S$ University of Salzburg, robert . huber@sbg. ac . at

ILMU Munich and ETH Zurich, lukas.rudolph@gsi.uni-muenchen.de 


\section{Introduction}

A large literature revolves around the contrast between voting for parties and voting for individual candidates, examining its consequences for voters, elites, and the nature of representation (e.g., Carey 2009, Colomer 2011; Shugart|2013). A core argument suggests that open ballot structures, where parties run more than one candidate each and voters can indicate preferences for individual politicians, foster intra-party competition and, as a result, non-policy types of representation (e.g., Carey and Shugart 1995; Crisp et al. 2004; Franchino and Mainenti 2013; André, Depauw and Shugart 2014). Policy-related deviations from the party line, on the other hand, are not regarded as a widespread form of appealing to voters (at least not in parliamentary systems of government), for several reasons. First, politicians and voters may sort into parties based on policy preferences, implying weak heterogeneity and little demand for divergence (Krehbiel 1993). Second, to maintain the party brand, party leaders may counteract deviations from the party line by means of ex ante screening or ex post monitoring (Bowler, Farrell and Katz 1999; Strøm, Müller and Bergman 2006; Carroll and Nalepa 2020). Third, the typical voter may have too few incentives to become sufficiently informed to choose individual candidates based on their policy positions.

What if an issue that crosscuts existing party lines becomes salient to the public, though? In this case, citizens may be attracted to candidates who share their view on the issue, albeit not the ones held by the candidates' party. Nevertheless, we would expect that voters continue to take into account party-level factors when making a choice. On top of that, they need to factor in the impact a candidate may have on the future party position on the issue. Given these considerations, which voters change their party choice between closed and open lists, and under which conditions would a party fielding candidates with heterogeneous positions gain votes? We examine these questions both theoretically and empirically. We derive implications from a formal model of vote choice 
and present results from a survey experiment linked to debates over immigration policy in Germany.

Blumenau et al. (2017) recently introduced the argument that open-list PR may electorally favor parties that are internally divided on salient issues, when compared to the closed-list PR case. Their empirical evidence comes from a survey experiment in the UK, presenting respondents a fictitious European Parliament election with four experimental groups that differ in the list type (open vs. closed list) and information provision (yes vs. no) on candidate positions regarding Brexit. Results suggest that the British Conservative Party indeed gains votes at the expense of UKIP under open rather than closed lists, given information on candidate positions. This innovative study points to an important and so far overlooked research problem but provides only initial answers.

Starting from the question of whether the results from Blumenau et al. (2017) generalize, we extend this line of inquiry in four ways. First, their theoretical argument remains vague with regard to how voters weigh party-level and candidate-level factors when making a choice. It suggests that voters may have an expressive motivation, where the "attractiveness of the parties" matters under closed lists, but the "attractiveness of the candidates" is decisive when open lists are used (Blumenau et al. 2017: 811).1. At the individual level, they expect "voters who have preferences close to a mainstream party on one dimension, but close to the niche party on a cross-cutting dimension, to be most likely to change party when moving from closed to open lists (assuming that the candidates of the mainstream party differentiate)" (Blumenau et al. 2017: 821). Our formal model clarifies how voters trade off party valence and spatial proximity to the party, while the elected candidate may at the same time influence the party position. From this, we derive predictions regarding which voters may be swung by a change in electoral rules, which are both more general and more precise.

$1 \quad$ They also posit a second mechanism linked to strategic voting, but the experimental evidence favors the expressive voting story. 
Second, we replicate the survey experiment in a different context, focusing on immigration policy in Germany. During the European refugee crisis, mainstream parties faced an immigration-skeptic electorate while being internally divided over the appropriate level of immigration. In Germany, this setting contributed to the success of a new populist right-wing party, the Alternative for Germany (AfD). Under the closed-list system, it successfully contested mainstream parties on the immigration issue. We ask whether an open-list system would reduce the electoral threat the challenger party poses to established competitors. In addition, the proposed mechanism should, in principle, also apply to the Green Party, which is the cohesive pro-immigration counterpart of the AfD. They may lose pro-immigration voters to other parties under an open-list system though the effect might arguably be weaker as the Greens' policy position resonates with fewer voters overall, it differs less from the status quo, and the closest competitor parties have very similar stances. Third, our experimental design allows us to test additional observable implications. We expand the set of treatments by adding an emphasis frame condition to change citizens' perceptions of candidate influence on the party position. Fourth, we expand the experimental setting and let respondents vote for a second time in an open-list setting, following a first-round choice between closed lists (and vice-versa). This enables us to conduct a within-subject analysis and map individual voters' transitions between parties. Thereby, we provide both between and within individual evidence to test our theoretical propositions.

Our core empirical finding is that, given information on the immigration positions of candidates, under open lists the largest mainstream party on the center-right (CDU/CSU) realizes a net gain of 4 percentage points, whereas the immigration-skeptic AfD loses $25 \%$ of its voters (6 percentage points) when compared to voting under closed lists. We also find evidence for two important and distinctive implications of our theoretical model. First, shifts in vote shares can be accounted for by voters who are close to indifferent 
between their two top-ranked parties, where one of the parties is homogeneous, the other one heterogeneous. As expected, citizens who strongly prefer one party are unlikely to change their voting behavior. Second, the above effect is most pronounced for voters with an extreme to moderate, but not too extreme, stance on immigration policy — the set of individuals who are most likely to be indifferent between the homogeneous extreme and some other, heterogeneous party. Within-subject analyses reinforce the findings from the between-group comparison. When offered open lists in a the second round, voters move predominantly to the (heterogeneous) party that is closest to the (cohesive) party on the immigration dimension. The individual-level analysis also suggests that a substantial amount of voters of the cohesively pro-immigration Green Party move to other parties when given a candidate choice in the form of open lists. Taken together, our analysis points out that open lists can alter the relative electoral strengths of parties with homogeneous vs. heterogeneous candidate "menus" across a wide range of contexts.

\section{Theory}

We use a canonical model of vote choice where voter utility is a function of the voter's spatial proximity to the party or candidate in the policy space and party or candidate valence. Individuals vote for the option that maximizes utility. $\left.\right|^{2}$ We intentionally employ a broad meaning of valence (Stokes 1963, 1992). It encompasses judgments of voters about non-policy characteristics of parties/candidates that are valued by all voters, such as competence, skills, and integrity (Ansolabehere and Snyder Jr. 2000; Groseclose 2001; Schofield and Sened 2006; Stone 2017). In addition, since the argument focuses on a single salient issue (here immigration), our notion of valence also includes spatial proximity on other dimensions of the policy space (such as economic policy).

$2 \quad$ We should stress that we model voters as outcome-motivated (they want to affect policy outcomes or get represented when voting for candidates or parties) but sincere. 
Our main interest lies in analyzing whether having a choice among individual candidates with a deliberate policy position (here pro- or anti-immigration stance) affects which party is supported. To begin with, let $u_{i j}$ be the utility of voter $i$ from casting a vote for choice alternative $j$, that is — with slight abuse of notation - a party list in a closed-list system, or, under open list, a candidate fielded by a party. Let $\lambda$ and $\gamma$ be indicators for the contexts we are interested in: $\lambda=0$ refers to a closed-list system where votes are cast only for parties; $\lambda=1$ captures an open-list environment. Representation-motivated or policy-based voting for individual candidates requires information on candidates beyond what voters know about the parties these candidates belong to. We therefore contrast a situation where voters are aware of the pro- or anti-immigration stance of candidates $(\gamma=1)$, to a situation where no candidate-specific information is available so that the party label is the only cue $(\gamma=0) !^{3}$ Voter $i$ 's utility from the vote for a party list or candidate $j$ then is:

$$
u_{i j}=v_{i j}-\beta\left(x_{i}-\left[y_{j}+\Delta_{j}\right]\right)^{2}
$$

where $x_{i}$ is the voter position on the relevant issue, here immigration, $y_{j}$ is the position of the party on immigration, and $\Delta_{j}=\gamma \lambda z_{j}$ is the expected change in the party's position on immigration (as perceived by the voter) when a pro- or anti-immigration candidate $j$ gets elected in an open-list system. The term $v_{i j}$ is a summary term that combines both the voter's evaluation of the party/candidate in terms of non-policy attributes and salient positional issues other than immigration 4 Parameter $\beta>0$ is the weight of spatial proximity on the immigration dimension.

The squared term in equation (1) captures voter evaluations of the choice options on

3 Candidate names could serve as a signal if they are suggestive of a candidate's sex, age, or ethnicity and if these attributes correlate with candidate positions on the issue in question. In the experimental setup below, we control for any such effects.

4 Lumping together these components assumes that information about candidate positions on immigration is not informative as to the positioning of parties/candidates on any other salient dimension. 
the immigration dimension, which differ across institutional settings. In closed-list environments, voting for candidates is not feasible so that the relevant reference is the party position, $y_{j}$. Also, under open list, building reasonable expectations about how parties change or, more generally, how representation changes with electing specific candidates into office, requires information about candidates' policy stances or other relevant candidate attributes. Therefore, if there is no such information, we expect $\Delta_{j}$ to be zero.5 Note that the mere fact that voters receive information on candidates' stances on immigration policy may also impact — in addition to spatial proximity — on the salience of the immigration dimension in the voter's utility (a larger $\beta) .6$

We assume that individuals vote for the party or candidate that maximizes the latent utility. Hence, individuals who rank the same two choice options as first and second are separated by a single point of indifference or cut point on the issue dimension. Intuitively, if the parties are rated equally on the summary evaluation $v_{i j}$, the cut point is located at the midpoint of the parties' positions. If one party has a valence advantage, the cut point is closer to the disadvantaged than to the advantaged party, since the latter can compensate for some of the spatial distance by valence. More specifically, the point of

$5 \quad$ In a more complex setup, one could think of the expected change in the party position as

$$
\Delta_{j}=\gamma \lambda z_{j}+\lambda z_{j}^{\prime}+\gamma z_{j}^{\prime \prime}
$$

Then $z_{i j}^{\prime}$ would capture the expected change in party positions under open list as compared to closed list if no information on the immigration preferences of individual candidates is available. For instance, voters might have reasons to believe that immigration hard-liners are more popular in the electorate and therefore more likely to be elected in an open-list setting. On the other hand, $z_{i j}^{\prime \prime}$ captures the expected change in the party position in a closed-list environment due to the provision of (more) information about candidates. For example, voters might update their prior about a party's policy position when they learn about the distribution of policy stances of the candidates presented.

6 Compare empirical findings that media coverage of immigration topics predicts extreme right party success (Walgrave and De Swert 2004), and that the impact of immigration-related spatial distance on party choice increases after immigration reforms (Abou-Chadi and Helbling 2018). 
(I) Voters with strong preference for $\mathrm{B} \quad v_{i B}>>v_{i A}$, or, $v_{i B}>v_{i A}$ and $\beta \approx 0$

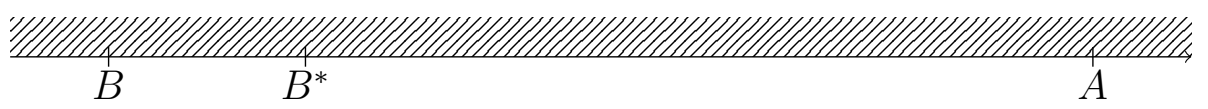

(II) Voters without strong party preference

(a)

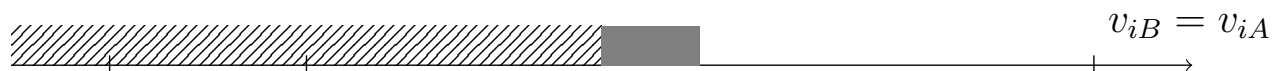

(b)

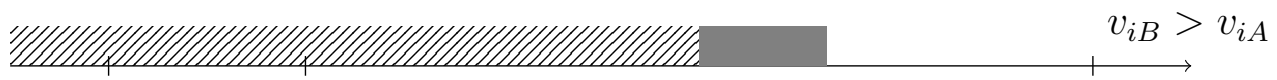

(c)

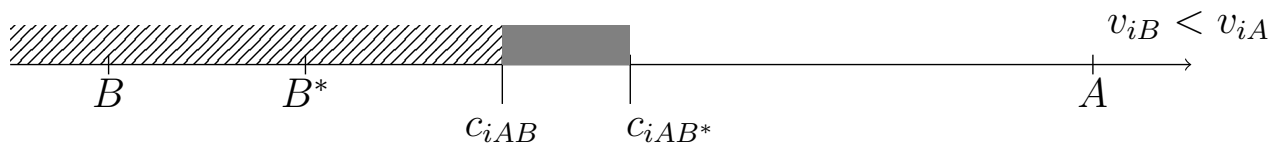

(III) Policy shift of B is large

$v_{i B}=v_{i A}, \Delta_{B}$ large

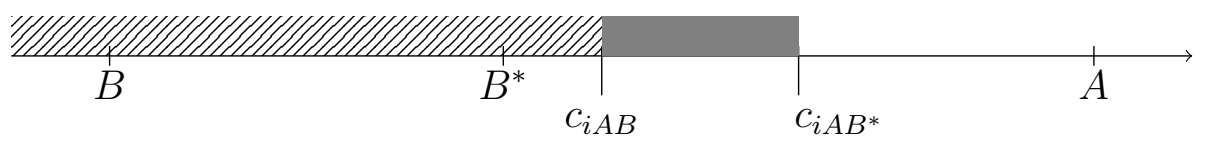

Figure 1: How heterogeneous party $B$ wins votes from cohesive party $A$ when lists are open. Hatched range of ideal points: voters choosing party B under closed-list ballot; gray range: voters with incentives to switch votes from A to B under open-list ballots

indifference between two options, parties or candidates, $j$ and $k$, is given by

$$
c_{i j k}=\frac{y_{j}+\gamma \lambda \Delta_{j}+y_{k}+\gamma \lambda \Delta_{k}}{2}+\frac{v_{i j}-v_{i k}}{2 \beta\left(y_{k}+\gamma \lambda \Delta_{k}-y_{j}-\gamma \lambda \Delta_{j}\right)},
$$

provided that the choice options are different, $y_{k}+\gamma \lambda \Delta_{k} \neq y_{j}+\gamma \lambda \Delta_{j}$.

Now, what is the effect of moving from a closed-list to an open-list system? Our key interest is in differences in voting behavior under open and closed lists at both the individual and the aggregate level: First, are there individuals who — under open list — vote for a candidate of a party they would not have voted for under closed list? Second, does this also result in differences in parties' vote shares between closed and open lists? 
We start at the individual level and consider whether the utility differences between institutional settings result in vote switching between parties. Figure 1 provides the intuition of the argument, using an example of voters deciding between a cohesive party $A$ and a party $B$ with heterogeneous positions. In this example, the policy position of $\mathrm{A}$ is located to the right of that of $\mathrm{B}$, but the results are symmetric in the opposite case. In the first panel, voters are strongly predisposed toward $B$ above and beyond their proximity to parties on the immigration issue. Alternatively, they may have just a weak preference for $B$ but do not care about immigration policy. In either case, this group votes for $B$ under both closed and open ballots.

In the second panel, immigration policy is salient and the valence terms are more balanced so that voters for $A$ and $B$ are separated by cut points $c_{i A B}$. If the voter expects party $B$ to shift in the policy space to the right by $\Delta_{B}$ as a result of a vote for a right-leaning candidate of party $B$, she will vote for the party $B$ candidate if her ideal point is to the left of $c_{i A B^{*}}$. Put differently, the cut point shifts by $\Delta_{B} / 2$, implying that the voter switches parties if her ideal point falls into the interval $\left[c_{i A B}, c_{i A B^{*}}\right]$. As long as the voter is nearly indifferent overall, this conclusion applies regardless of whether the voter is strictly indifferent between $A$ and $B$ on valence grounds (scenario IIa) or the voter slightly favors $B$ to $A$ (as in scenario IIb, or vice versa as in IIc) for reasons other than her immigration platform. In the latter cases, the cut point is ex ante shifted from the midpoint toward $A$ (or $B$ ). Finally, the third panel is similar to scenario IIa, with the qualification that the expected shift of $B$ on the issue dimension is larger. As a consequence, the range of ideal points where voters have incentives to abandon $A$ in favor of a candidate of $B$ also increases 7

$\overline{7} \quad$ Specifically, the change in the cut point is:

$$
\Delta c_{i j k}=\frac{\Delta_{j}+\Delta_{k}}{2}+\frac{v_{i j}-v_{i k}}{2 \beta}\left(\frac{1}{\left(y_{k}+\Delta_{k}\right)-\left(y_{j}+\Delta_{j}\right)}-\frac{1}{y_{k}-y_{j}}\right) .
$$


Altogether, a party may thus attract votes under open-list ballots when fielding candidates expected to alter the party's position when elected. If $j$ is to the left of $k$ and with the election of a right-leaning candidate - is expected to move right toward $k$, the cut point shifts to the right 8 As a consequence, voters who are by and large indifferent between $A$ and $B$ are most likely to switch from $A$ to $B$ if their ideal points are near the center between the two parties.

To answer the second question from above, regarding the size of shifts in aggregate vote shares, we need to take into account the voter distribution. This is because the aggregate effect will depend on how densely populated the gray-shaded intervals in Figure 1 are. Also note that one would expect the $\Delta_{j}$-terms to systematically vary over parties or contexts. Voters' expectations about elected candidates' influence may, for example, form on the basis of how they perceive intra-party decision-making processes. Likely, some parties appear less leadership-centered and more inclusive than others in that regard.

To sum up, we provide three observable implications of the argument:

Implication 1 Parties with a heterogeneous candidate pool may gain votes from parties with a homogeneous candidate pool in an open-list setting as compared to a closed-list setting.

It is worth emphasizing that, in line with the discussion above, we deliberately say "may gain". At the individual level, the effect depends on whether the expected change in the party platform is sizable when compared to the valence differential. For instance, we would not expect to see a heterogeneous party gaining votes from any homogeneous party if the first has a large valence disadvantage in the entire electorate.

Implication 2 The above effect is stronger if voters associate candidate votes under open-list ballots with larger shifts of party positions.

\footnotetext{
$8 \quad$ When both parties offer a range of candidates differing in their policy stance, the effect will depend on the relative size of the expected changes in party positions. If $\Delta_{j}=-\Delta_{k}$ there is no incentive to shift votes.
} 
Implication 3 Individuals who are close to indifferent between their two top-ranked parties $A$ and $B$ are more likely to change their vote from homogeneous party $A$ to heterogeneous party $B$ if their policy preferences are near the midpoint between those of $A$ and $B$.

We next discuss how these implications of the theoretical model translate into hypotheses on shifts in party vote shares and individual-level vote switching in the specific context of our experiment, the strengthening of the German right-wing party AfD following the European migrant crisis.

\section{Case-specific expectations}

The theoretical arguments above refer to the more general case of an issue that mainstream parties are internally divided on and challenged by (potentially new) competitors who take a clear stance on the issue. Immigration politics in Germany following the recent European migrant crisis is a fitting case. The far-right populist Alternative for Germany (AfD), founded in 2013 as a Euroskeptic party, shifted its focus to immigration and presented itself as the sole alternative to established parties, propagating a clear and unambiguous immigration-skeptic position. At the same time, for electoral and other reasons, most other parties were characterized by substantial internal divisions over the level of immigration, immigrant rights, family reunification, and other issues. The only exception to this rule was the Green Party, for which intra-party dissent on the issue was rather low-key. The most prominent critic of the Green's immigration policy position was Boris Palmer, mayor of Tübingen, a city with less than 100,000 inhabitants. His statements were openly criticized by key politicians in the party. Most notably, party leader Özdemir and Baden-Württemberg's state-level prime minister Kretschmann marginalized his position, arguing that Palmer had no authority on this issue and merely spoke for 
himself (Spiegel 2016). Contrary to other parties, the Green Party was the only major German party that appeared as very unified on the asylum-friendly end of the policy space.

It has been argued that the popularity of the AfD (and other right-wing populist parties in Europe) is not only a consequence of a public that is polarized on migration policy but also has other roots such as conservative views on morality and social issues, or a general anti-elite or populist sentiment (?). If true, this does not contradict our argument, as our theoretical model subsumes migration-unrelated motivations under the baseline utility captured by the valence term. For instance, a protest appeal of the AfD may reduce the valence disadvantage of the party among some voters, or contribute to its valence advantage among others. We would still expect an effect of ballot structure as long as there is a sufficient number of voters who remain fairly indifferent between the AfD and another party and whose immigration positions fall in the respective switching intervals.

As a starting point and motivation for the empirical application, we first consider the prevalence of attitudes toward immigration in the public using data from a 2017 postelectoral survey collected as part of the German Longitudinal Election Study (GLES) (Roßteutscher et al. 2019). In the survey, respondents were asked to place both themselves and major parties on an 11-point scale ranging from "facilitate immigration" to "restrict immigration." As Figure 2 shows, the AfD separates itself from the other parties with a decidedly immigration-skeptic view, a perception that is shared by a large part of the respondents. Christian Democrats (CDU/CSU) and Liberals (FDP) are perceived as considerably more moderate. However, citizens differ greatly in their perception, hinting to possible intra-party heterogeneity of views in those parties. Remarkably, while over $90 \%$ of respondents are ready to place the CDU/CSU, we also observe widespread perceptual disagreement on its location. On the left-hand side, the far-left party Die Linke 
(The Left) and Greens occupy the most liberal positions (with almost identical median perception). However, citizens vary a lot more when it comes to locating The Left than the Greens. This may be the case because politicians from The Left, especially the prominent parliamentary party group co-leader Sahra Wagenknecht, have also expressed concerns about immigration.

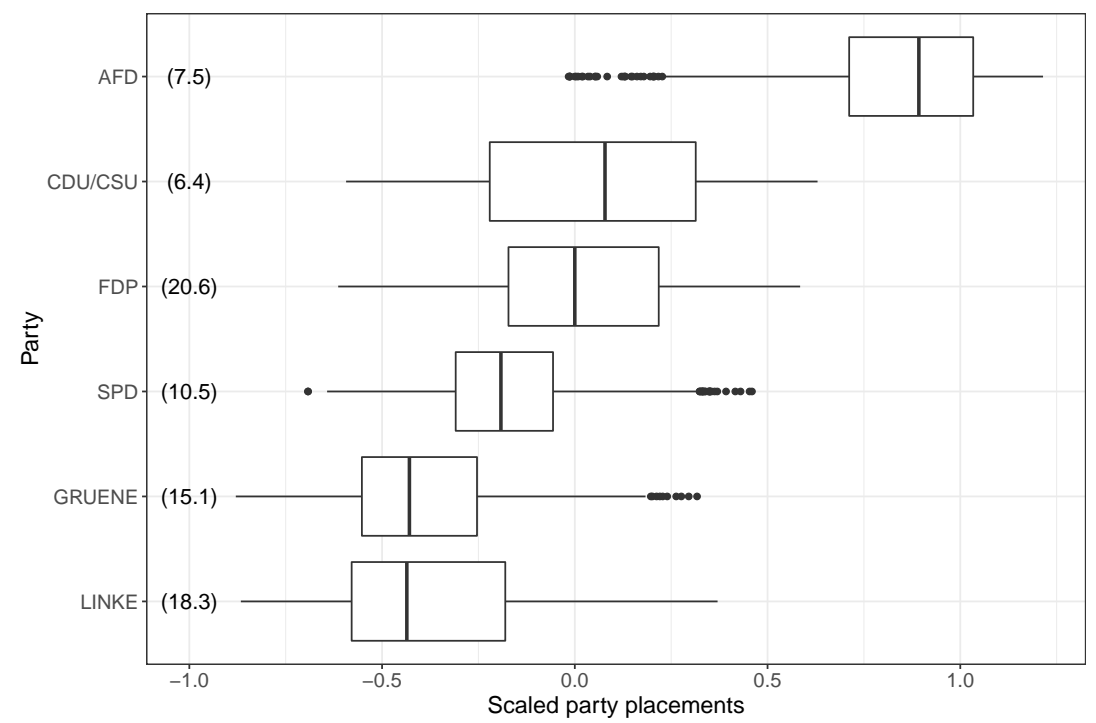

Figure 2: Perceived party positions on immigration. The figure shows box plots (median, inter-quartile range, and $1.5^{*} \mathrm{IQR}$ ) of perceptions, re-scaled using Aldrich-McKelvey scaling (using basicspace R package, Poole et al. (2016)). Boxes are based on $N=1384$ respondents who place all parties and themselves, have variation in party placements, and positive scaling weights. Figures in parentheses are percentages of missing placements among all $N=2042$ respondents. Placements of CDU/CSU refer to CSU in Bavaria and to CDU elsewhere. Data: GLES 2017 (Roßteutscher et al. 2019).

The far-right AfD has potential to attract votes with its clear anti-immigration platform: approximately $50 \%$ of respondents place themselves to the right of the CDU/CSU position (Figure 3). At the same time, the large gap between CDU/CSU and AfD also suggests that under an open-list ballot, Christian Democrats might (re-)gain votes from the populist AfD: There is a sizable segment of the electorate with positions falling between $\mathrm{CDU} / \mathrm{CSU}$ and AfD who - if those are their top 2 preferred parties — could be inclined to vote for a migration-skeptic CDU/CSU candidate under an open-list ballot. Certainly, 
this presupposes that, first, voters expect that the election of an immigration-skeptic candidate can effectively alter the party line of Christian Democrats; secondly, the AfD is perceived as homogeneous and the candidates it can field as likewise immigration-skeptic. While vote switching is most likely for the closest party on the immigration dimension, the CDU/CSU, our argument also implies the possibility of vote switching from the AfD to other parties, provided that the other party has a heterogeneous candidate pool and, together with the $\mathrm{AfD}$, is one of the two top-ranked parties.

Should we expect a similar pattern on the left-hand side of the political spectrum? On the one hand, one could argue that the Green Party presents itself and is perceived as a party with a highly unified liberal position on immigration. Consequently, under an openlist as compared to closed-list ballot, voters with a quite liberal stance on immigration might be tempted to support an immigration-friendly candidate of the Social Democratic Party or The Left if they expect their candidate vote to effectively alter the party line of Social Democrats or The Left. At the same time, as Figure 3 suggests, there is only a small segment of the electorate that is located between the Greens on the one hand and Social Democrats and The Left on the other.

The question remains to what extent the large pool of rather immigration-skeptic citizens can actually be targeted by both the CDU/CSU and the AfD. If those voters were strongly attracted exclusively to one party or any of the other parties, there would be little scope for any ballot structure effects. Figure 4 shows that this is not the case. In the survey experiment, we asked respondents to rate all parties on a standard 11-point scale. We use these scalometer ratings to proxy overall party preferences, that is utilities $u_{i j}$ from a vote for a party list. In the sample of our survey experiment, approximately one out of ten respondents can be classified as indifferent between CDU and AfD $9^{9}$ More importantly, this share is larger among more immigration-skeptic voters, with about one

$9 \quad$ We classify voters as indifferent between AfD and a second party if the both parties receive one of the two highest ratings and ratings do not differ by more than one point on the 11-point scale. 

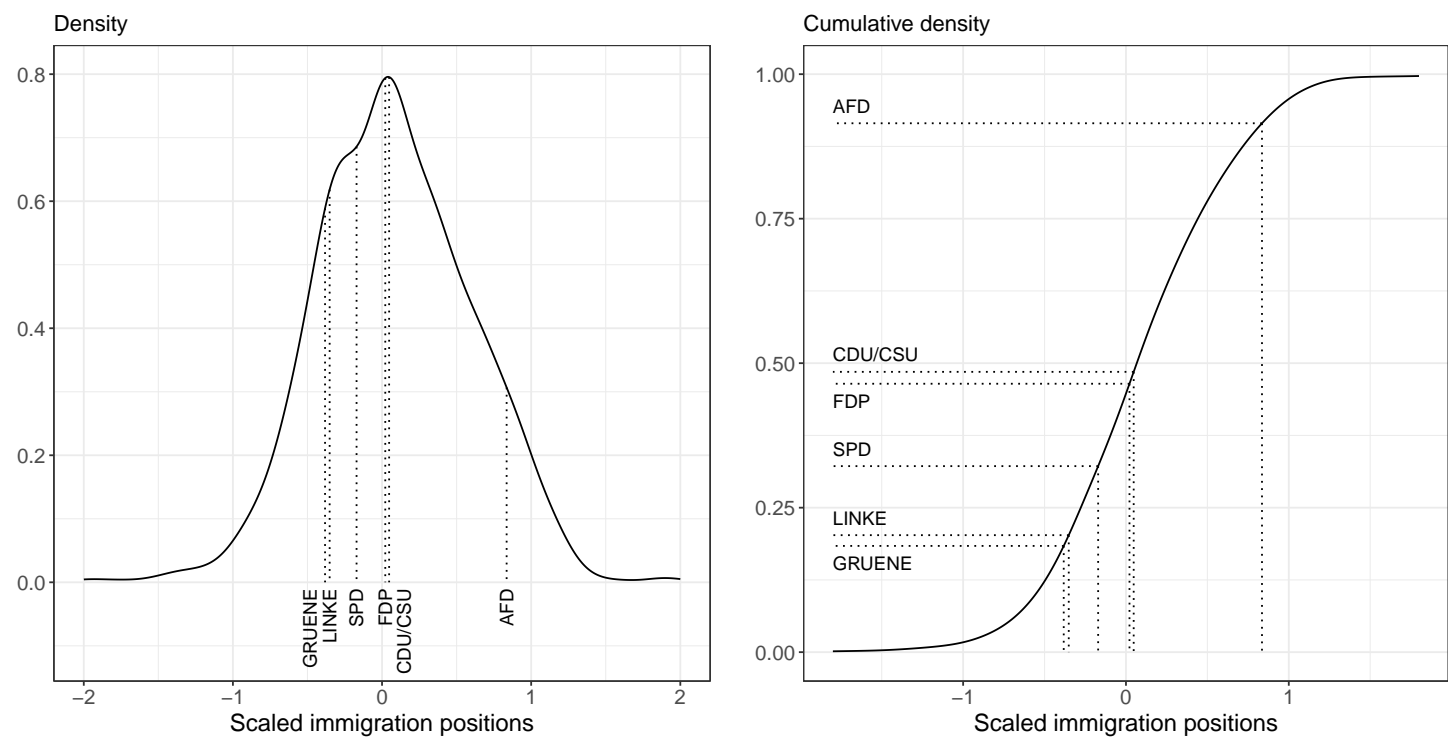

Figure 3: Distribution of voter and party positions on immigration based on AldrichMcKelvey scaling. Data: GLES 2017. For details, see notes to Figure 2 .

in six citizens near the right end of the scale rating both parties similarly. For the Green Party, even if there is a much smaller pool of pro-immigration respondents in total, Appendix Figure A.2 shows that about $21 \%$ of voters can be classified as indifferent between Greens and SPD, and those respondents are slightly more often found towards the pro-immigration end of the policy space. Taken together, these analyses suggest that immigration policy is a good test case for the general arguments outlined above, for both ends of the political spectrum.

We can now restate the model implications from above, tailored to the context of our empirical case:

Hypothesis 1 On aggregate, AfD will receive fewer votes and $C D U / C S U$ more votes under open lists than under closed lists.

Hypothesis 2 The effect stated in Hypothesis 1 is stronger when attention is drawn to the notion of parties taking into account the electoral support of candidates when deciding about policy direction. 


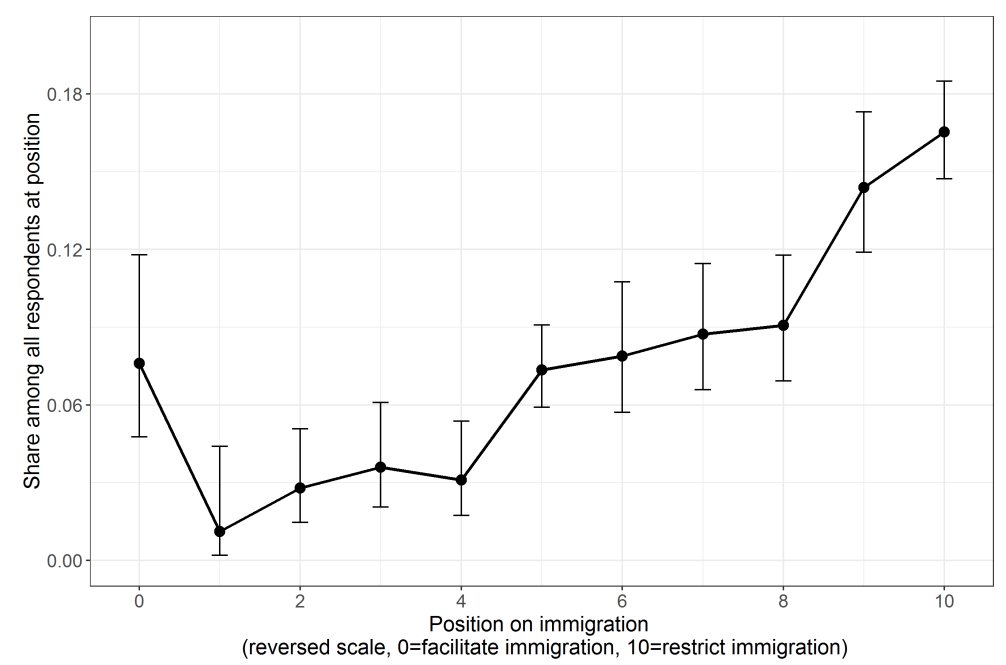

Figure 4: Share of respondents indifferent between CDU and AfD, by self-reported immigration position.

Hypothesis 3 From among the voters who are indifferent between AfD and $C D U / C S U$, vote losses by $A f D$, and respectively vote gains by $C D U / C S U$, are largely due to voters whose immigration positions are in the middle between those of the two parties.

We expect weaker effects at the pro-immigration end of the scale where immigrationfriendly voters may be drawn away from a unified, immigration-liberal Green Party when they are offered the option to vote for a pro-immigration candidate of some other party.

Hypothesis 4 The above effects are weaker for the case of Greens losing votes to Social Democrats or The Left under open list.

\section{Research Design}

We embedded the experimental design in an original nationally representative survey. The survey was fielded by the survey company Lightspeed between January 11 and February 19, 2019, with 6,600 respondents recruited from the company's online panel applying quotas on age, gender, education, and region ${ }^{10}$ In other words, the sample is representative $\overline{10}$ See the respective section in the Appendix for more information on the distribution of these variables. 
of the German voting population along these quotas. The median duration to finish the survey was 6.4 minutes. Responses shorter than 4 minutes were excluded ex ante by the survey company.

Comparisons of preferences voiced by our respondents compared to surveys applying random sampling allow us to further judge the external validity of our study. With respect to political leanings, a question on party preferences (cf. intercepts in Table 2, which correspond to vote shares in a closed-list setting without information) yields answers comparable to German opinion polls ${ }^{11}$ Assuming a margin of error of around 3 percentage points, only CDU/CSU voters are slightly underrepresented and The Left and AfD voters are slightly overrepresented in our survey. Overall, this makes us confident that results from the survey experiment can be generalized to the German population.

\section{Experimental design}

We randomly assigned respondents to one of five treatment conditions (see Table 1), before eliciting their vote in a hypothetical German federal election ("Bundestagswahl"). The first four treatment conditions constitute a $2 \times 2$ design crossing over closed vs. open ballot, and information vs. no information on candidate's position on the immigration issue, similar to the one in Blumenau et al. (2017).

First, to mimic respondents' choice in a closed-list PR vs. open-list PR electoral system, we displayed a vertically ordered list of parties and, within parties, candidates. In the closed-list condition, respondents had to vote for one of the party lists. In the open-list condition, respondents had to select a single candidate within one party. In the introduction, respondents were informed that in the closed-list condition any seats

11 One of the most renowned regular German opinion polls saw CDU/CSU at 28\%, SPD at $15 \%$, AfD at $15 \%$, Greens at $20 \%, \mathrm{FDP}$ at $9 \%$, The Left at $8 \%$, and other parties at $5 \%$ (survey by Infratest dimap with 1,051 respondents, dual frame, CATI) on January 24, 2019 (see https:// Www.wahlrecht.de/umfragen/dimap.htm). Note that we only allowed voters to voice preferences among the six parties represented in Parliament. 
the party gains are assigned to candidates based on list rank, whereas in the open-list condition seats are assigned based on within-party candidate vote shares.

Secondly, we varied whether respondents received information — whether they were informed on a specific immigration policy issue and the issue positions of all the candidates on the ballot. We presented information on a concrete issue under public debate related to immigration policy — family reunification of asylum seekers. Candidates supported either more lenient or more strict handling of family reunification compared to the actual status quo. ${ }^{12}$ We chose this as a salient issue in immigration politics, as at the time there was an ongoing debate about the issue in the German Bundestag, so it seemed plausible that candidates would state their views on this topic during a campaign. Following our argument, we varied whether parties were internally divided on the issue. For most parties (CDU/CSU, SPD, FDP, The Left), we ensured that their lists contained two candidates who supported more strict position, and two candidates who supported more lenient positions on family reunification $\sqrt{13}$ For the AfD, we presented all candidates as having a more restrictive position than the status quo. We mimicked this procedure for the Green Party and presented all candidates as more lenient than the status quo. We confronted respondents with this information as follows: First, we introduced and explained the ongoing discussion and the legal status quo on the specific policy. On the ballot, the information was then randomly placed next to the name in brackets (see Figure 5).

A final (fifth) treatment group received an emphasis frame (Druckman 2001). Respondents voted with an open ballot and with information on candidate positions concerning immigration, i.e., identical to the fourth group. The emphasis frame contained additional information on how parties operate under open lists. It specifically highlighted that po-

\footnotetext{
12 Respondents were informed that, as of the time of fielding the survey, up to 1,000 family reunifications per month for all refugees with subsidiary protection were allowed in Germany.

13 This split approximates the actual distribution of opinions within the parties. While the share of proponents and opponents of extending family reunifications might vary by party, neither position was marginalized. For the AfD and the Greens, candidates with more lenient or restrictive positions would have been unlikely.
} 
litical parties will consider the electoral performance of specific candidates in their future policy decisions.

Within each treatment condition, respondents were asked to cast a vote in a hypothetical election for the German Bundestag. We explicitly stated that the context referred to the second, list-PR vote (so-called Zweitstimme) of the German mixed-member system. All respondents were asked to pick one party or, in the open-list treatment, one candidate. Vote choice is our dependent variable.

Table 1: Overview of treatment condition

\begin{tabular}{|l||l|l|l|l||l|}
\hline Treatment group & 1 & 2 & 3 & 4 & 5 \\
\hline \hline Ballot structure & Closed & Closed & Open & Open & Open \\
\hline $\begin{array}{l}\text { Information on candidate posi- } \\
\text { tions }\end{array}$ & No & Yes & No & Yes & Yes \\
\hline $\begin{array}{l}\text { Emphasis frame on party strategy } \\
\text { in open lists }\end{array}$ & No & No & No & No & Yes \\
\hline \hline Percentage of sample & 20 & 20 & 20 & 20 & 20 \\
\hline
\end{tabular}

In order to increase context validity, all respondents were shown a ballot that resembled the real election ballot regarding ballot title and introduction, vertical ordering of parties, listing of the six major parties (i.e., CDU (CSU for Bavarian respondents), SPD, AfD, Greens, FDP, Die Linke) at the top of the ballot, and listing of four candidates of each party ${ }^{14}$ Concerning candidate names, we chose 24 randomly combined first and family names and ensured that there were no similarities with persons of public interest, such as politicians or celebrities. We used twelve female and twelve male names and restricted randomization so that no list had exclusively male or female politicians.

Figure 5 displays screenshots of how the closed list/no information (treatment condi-

14 We randomly ordered the parties, as we wanted to exclude any spurious relation of ordering with our treatment hypotheses; we showed four instead of three candidates to balanced positions in parties; and we listed candidates vertically, such that ballots resembled an open-list design, excluding ballot design effects. 
tion 1, top panel) and the open list/information (treatment condition 4, bottom panel) were actually displayed to respondents.

This design allows to assess differences in the aggregate voting patterns across treatment groups. To elicit individual level changes, respondents receive a second round of the above described experiment. In this second round, we keep the level of information constant and vary the electoral system. In other words, individuals in treatment group 1 (see Table 1) receive treatment group 3; individuals in treatment group 2 receive treatment 4 and vice-versa. This design allows better understanding how voters' vote choice changes (if at all) when facing a different electoral system.

Before analyzing the experimental data, we made sure that randomization worked properly. Tables A.2, A.3, and A.4 in the Appendix provide balance tests. Table A.2 shows that there is no systematic difference in any of our covariates by treatment but age. In other words, there is no systematic difference in gender, education, employment, income, or region, whereas individuals receiving information were slightly younger (1.5 years) than others. Additionally, we checked whether our $p$-values follow a uniform distribution, which they writ large do (see Figure A.3 in the Appendix). ${ }^{15}$

\section{Estimation strategy}

We evaluate the effects of ballot type and information on vote choice using OLS regressions. Assuming linear probability is plausible in this case and comes with the advantage that we can interpret all coefficients as changes in percentage points. Our outcome variables $Y_{p}$ are binary indicators for whether a respondent selected party $p$ (closed-list treatment) or a candidate from that party (open-list treatment), where $p=\{$ Greens, The Left, SPD, FDP, CDU/CSU, AfD\}. Treatment conditions 1 to 4 are, following the

\footnotetext{
15 Given that our randomization worked satisfactorily, we present our experimental results without covariates. This comes with the advantage that the intercept directly provides a measure of a party's vote share in the control condition (closed list without information).
} 
a) Closed list without information

\begin{tabular}{|l|l|l|}
\hline 1. Jens Kühn & DIE LINKE \\
\hline 2. Julia Seifert & \\
\hline 3. Christian Arndt & \\
\hline 4. Eva Müller & AfD \\
\hline 1. Paul Seidel & \\
\hline 2. Claudia Lorenz & \\
\hline 3. Katrin Roth & \\
\hline 4. Daniel Barth & \\
\hline
\end{tabular}

b) Open list with information

\begin{tabular}{|l|l|}
\hline \multicolumn{1}{|c|}{ CDU } \\
\hline $\begin{array}{l}\text { 1. Jens Kühn } \\
\text { (Nachzug: } \text { mehr) }\end{array}$ \\
\hline $\begin{array}{l}\text { 2. Andrea Kruse } \\
\text { (Nachzug: weniger) }\end{array}$ \\
$\begin{array}{l}\text { 3. Michael Lutz } \\
\text { (Nachzug: weniger) }\end{array}$ \\
\hline $\begin{array}{l}\text { 4. Stefan Vogt } \\
\text { (Nachzug: mehr) }\end{array}$ \\
\hline $\begin{array}{l}\text { 1. Matthias Thiel } \\
\text { (Nachzug: mehr) }\end{array}$ \\
\hline $\begin{array}{l}\text { 2. Anna Schuster } \\
\text { (Nachzug: mehr) }\end{array}$ \\
\hline $\begin{array}{l}\text { 3. Christine Haas } \\
\text { (Nachzug: weniger) }\end{array}$ \\
\hline $\begin{array}{l}\text { 4. Christian Arndt } \\
\text { (Nachzug: weniger) }\end{array}$ \\
\hline
\end{tabular}

Figure 5: Screenshots of the treatment conditions closed list/no candidate information (top) and open list/ candidate information (bottom) as shown to survey respondents (excerpts with two parties only).

full-factorial design, analyzed by regressing indicators for each treatment condition (open list $(\mathrm{O})$; information $(\mathrm{I})$ ) and an interaction term separately on indicators of vote choice; that is, we estimate $Y_{p}=\alpha+\gamma I+\delta O+\theta I * O+\epsilon_{p}$. Treatment condition 1 (closed list, no information) is the baseline.

To test Hypothesis 3, we identify indifferent voters as those who rate the AfD (Greens) and a second party within one point on the 11-point rating scale, with at least one of the two ratings being the highest of that respondent. We additionally conduct subgroup 
analyses by self-stated respondent preferences on the immigration issue. For this, we split the sample and compare coefficient estimates from the above regression in the subsamples. Finally, to get at the effect of the open-list emphasis frame $(E)$, we conduct a comparison on our vote choice indicators among respondents in treatment conditions 4 and 5 . In other words, we use a dummy variable for having received the emphasis frame in a regression for all respondents of treatment groups $T=4$ and $T=5$, i.e., respondents who cast a vote on an open-list ballot and who were provided with information about candidates' issue positions, $\left.Y_{p}\right|_{T \in\{4,5\}}=\alpha+\gamma E+\epsilon_{p}$.

\section{Results}

We begin by testing the effects of list type and information on aggregate party vote shares. Next, we investigate whether the emphasis frame affects respondents. We then assess the extent to which voters who are indifferent between two parties behave according to our theoretical argument and by investigating whether immigration attitudes matter for candidate choice between our treatment groups. All these steps utilize the first round of our experiment. We conclude by assessing within-respondent movement across treatments, for which we rely on both rounds of our experiment.

\section{Effect of list type and information}

What is the effect of list type on support for cohesive parties? We begin with estimating average party support in the four different treatment conditions. With binary vote choice as the dependent variable, the second, third, and fourth rows of Table 2 provide estimates of the effect of Open Lists (vs. closed), of Information on candidates' policy position regarding migration (vs. no information), and of the interaction between both treatments on party vote shares. The first column captures the effects for cohesive (AfD and Greens) 


\begin{tabular}{lccccccc}
\hline & Cohesive & \multicolumn{5}{c}{ By Party } \\
& Parties & Greens & Left & SPD & FDP & CDU/CSU & AfD \\
\hline (Intercept) & $0.38^{* * *}$ & $0.18^{* * *}$ & $0.13^{* * *}$ & $0.18^{* * *}$ & $0.09^{* * *}$ & $0.23^{* * *}$ & $0.19^{* * *}$ \\
& $(0.01)$ & $(0.01)$ & $(0.01)$ & $(0.01)$ & $(0.01)$ & $(0.01)$ & $(0.01)$ \\
Open List & -0.02 & -0.01 & 0.01 & 0.02 & 0.01 & -0.02 & -0.01 \\
& $(0.02)$ & $(0.01)$ & $(0.01)$ & $(0.02)$ & $(0.01)$ & $(0.02)$ & $(0.02)$ \\
Information & 0.02 & -0.02 & -0.01 & 0.01 & -0.00 & -0.03 & $0.05^{* *}$ \\
& $(0.02)$ & $(0.01)$ & $(0.01)$ & $(0.02)$ & $(0.01)$ & $(0.02)$ & $(0.02)$ \\
Open List x Info. & $-0.07^{* *}$ & -0.02 & 0.01 & -0.00 & 0.00 & $0.06^{* *}$ & $-0.05^{*}$ \\
& $(0.03)$ & $(0.02)$ & $(0.02)$ & $(0.02)$ & $(0.02)$ & $(0.02)$ & $(0.02)$ \\
\hline Num. obs. & 5281 & 5281 & 5281 & 5281 & 5281 & 5281 & 5281 \\
\hline
\end{tabular}

Table 2: Effects of ballot type and information. Coefficients estimated from a linear regression of ballot type (open vs. closed list), provision of information (yes vs. no), and its interaction on party choice (binary indicator whether party in model header is voted for). Entries are unstandardized regression coefficients from linear regression models. Standard errors in parentheses. ${ }^{*} p<0.05$, ${ }^{* *} p<0.01,{ }^{* * *} p<0.001$.

vis-á-vis internally divided parties. As can be seen from Open List, and as theoretically expected, there is no significant change in vote shares based on the list type treatment. The estimates for Information allow us to detect effects of the information treatment on respondents' average party choice. For the first column, there is no significant effect, indicating that cohesive parties do not profit from information per se. Finally, in line with our core theoretical prediction, the interaction term is negative and statistically significant, indicating that cohesive parties receive a lower vote share in an open-list information setting compared to internally divided parties.

In a next step, we disaggregate the findings by party (column 2 to 7 ). Again, coefficients for Open List fail to reach statistical significance. With Information, there is a substantial and significant increase in AfD votes of around 5 percentage points (about $25 \%$ of their baseline support). As we noted in the theory section, providing respondents with information on family reunification may have increased the salience of the immigration dimension in vote choice ( $\beta$ in equation 1 ), which plausibly increases the AfD's vote 
share 16

The interaction of the two treatment dimensions is of most interest. We observe a positive coefficient for the CDU/CSU and a negative coefficient for the AfD, both significant at least at the $5 \%$ level. This indicates that compared to the informationin-closed-lists setting, the effect of having an open list boosts the CDU/CSU vote share by 4 percentage points, whereas the AfD loses 6 percentage points (interaction effect net of open-list effect). In other words, the AfD is losing around $25 \%$ of its voters in an open list - given that information on an immigration policy issue is provided - and it does so most likely to the CDU/CSU. Notably, a similar effect does not show up on the left of the political spectrum; the Green Party is not losing voters to The Left, SPD, or CDU/CSU, at least not at a statistically discernible level. These empirical findings corroborate our theoretical argument and provide evidence for Hypothesis 1 ${ }^{17}$ For the AfD, the interaction effect is of similar magnitude to the information treatment alone. This could indicate that while increasing the salience of issues that parties on the fringes of the political systems compete on (here: immigration) can make some voters vote for these parties, the very same voters can be "brought back" by an open-list ballot design.

\section{Emphasis framing}

We argued that one might believe that candidates' voting results impact their influence on policy making. Pointing this out to respondents will then affect their expectations about a change in party position and, consequently, who they vote for. In a fifth treatment condition, we therefore insinuated that political parties consider the electoral performance

Note that for very low salience of immigration $(\beta \approx 0)$ voter utilities over party lists $u_{i j}$ largely reflect valence-based predispositions towards parties $v_{i j}$, i.e. factors above and beyond immigration. If salience of immigration is low when no information is received, the large share of respondents rating the AfD lowest on the scalometer (30.5\%) is thus indicative of a valence disadvantage of the AfD. Hence, in line with the argument (cp. panels I and II in Figure 1), immigration-skeptic respondents may be inclined to vote for some other party when no information is received but switch to an AfD-vote in the information treatment, where immigration salience arguably is higher.

17 Using multinomial logistic regression yields similar results (see Table A.8 in the Appendix). 


\begin{tabular}{lccccccc}
\hline & Cohesive Parties & Greens & Left & SPD & FDP & CDU/CSU & AfD \\
\hline (Intercept) & $0.30^{* * *}$ & $0.13^{* * *}$ & $0.15^{* * *}$ & $0.20^{* * *}$ & $0.10^{* * *}$ & $0.24^{* * *}$ & $0.18^{* * *}$ \\
& $(0.01)$ & $(0.01)$ & $(0.01)$ & $(0.01)$ & $(0.01)$ & $(0.01)$ & $(0.01)$ \\
Open Info + & -0.00 & -0.01 & 0.01 & 0.01 & 0.00 & -0.02 & 0.01 \\
& $(0.02)$ & $(0.01)$ & $(0.01)$ & $(0.02)$ & $(0.01)$ & $(0.02)$ & $(0.01)$ \\
\hline Num. obs. & 2639 & 2639 & 2639 & 2639 & 2639 & 2639 & 2639 \\
\hline
\end{tabular}

Table 3: Effects of emphasis frame. Estimates draw on subsample of respondents receiving both the open list and information treatment, while $50 \%$ also received an emphasis frame. Coefficients estimated from a linear regression of the emphasis frame indicator (yes vs. no) on party choice (binary indicator whether party in model header is voted for). Entries are unstandardized regression coefficients from linear regression models. Standard errors in parentheses. ${ }^{*} p<0.05$, ${ }^{* *} p<0.01,{ }^{* * *} p<0.001$.

of MPs in their decisions on the party line. In Table 3, we directly compare respondents in the open-list information treatment to those who received the same treatment and additional information on potential strategic considerations. The additional emphasis of these considerations does not affect how respondents vote. In other words, this treatment does not significantly shift vote choice for any party above and beyond the open list $\times$ information effect, at least not at a statistically discernible level for our sample.

This could suggest that voters are already well aware of the effect dissenting MPs can have on the party line. However, the finding would also be consistent with the argument that voters have more expressive motivations: They are inclined to vote for candidates who represent their preferences on immigration irrespective of the impact they may have on the party line. In sum, there is no support for Hypothesis 2.

\section{Indifferent voters}

Our argument attributes shifts in voting behavior under different ballot structures to voters who are close to indifferent between their two top-ranked parties. Voters who strongly prefer one party for reasons unrelated to immigration policy are unlikely to 
change their voting behavior just because another party list offers a candidate with a preferred pro- or anti-immigration stance. In contrast, voters who are close to indifferent between two (or even more) top-ranked parties can potentially be moved if they receive additional information on candidates and if they can affect which candidates on the list get elected. In order to test the argument, we split samples and focus on voters who rank the AfD and any other party similarly high ${ }^{18}$ Excluding the fifth treatment group (receiving the emphasis frame), this gives a sample with $N=847$ indifferent voters.

\begin{tabular}{lcccccc}
\hline & Greens & Left & SPD & FDP & CDU/CSU & AfD \\
\hline (Intercept) & $0.07^{* * *}$ & $0.13^{* * *}$ & $0.14^{* * *}$ & $0.10^{* * *}$ & $0.17^{* * *}$ & $0.40^{* * *}$ \\
& $(0.02)$ & $(0.02)$ & $(0.02)$ & $(0.02)$ & $(0.03)$ & $(0.03)$ \\
Open List & 0.03 & 0.01 & -0.02 & 0.04 & 0.01 & -0.06 \\
& $(0.03)$ & $(0.03)$ & $(0.03)$ & $(0.03)$ & $(0.04)$ & $(0.05)$ \\
Information & -0.02 & -0.03 & -0.04 & -0.02 & $-0.08^{*}$ & $0.19^{* * *}$ \\
& $(0.03)$ & $(0.03)$ & $(0.03)$ & $(0.03)$ & $(0.04)$ & $(0.05)$ \\
Open List x Info. & 0.00 & -0.01 & 0.09 & 0.03 & $0.11^{*}$ & $-0.21^{* *}$ \\
& $(0.04)$ & $(0.04)$ & $(0.05)$ & $(0.04)$ & $(0.05)$ & $(0.07)$ \\
\hline Num. obs. & 847 & 847 & 847 & 847 & 847 & 847 \\
\hline
\end{tabular}

Table 4: Subgroup effects of ballot type and information for voters indifferent between the AfD and any other party, while ranking these parties highest. Coefficients estimated from a linear regression of ballot type (open vs. closed list), provision of information (yes vs. no), and its interaction on party choice (binary indicator whether party in model header is voted for) for this subgroup. Entries are unstandardized regression coefficients from linear regression models. Standard errors in parentheses. ${ }^{*} p<0.05,{ }^{* *} p<0.01,{ }^{* * *} p<0.001$.

Table 4 provides the regression results, again presenting one model each for the different party vote shares. Starting with the AfD results, unsurprisingly, $40 \%$ of respondents who are indifferent between AfD and some other party actually vote for the AfD in the control setting. Receiving information on the immigration positions of candidates increases the AfD's vote share by 19 percentage points (.19). This effect is mitigated in an open-list scenario with information on candidate positions, where the AfD vote share 18 How we operationalize indifference is described in Footnote 9 
decreases by 21 percentage points. Where do these voters move to? In this subsample, it is again the $\mathrm{CDU} / \mathrm{CSU}(.11)$ but also the $\mathrm{SPD}(.09$; p-value $=0.051)$ that gain substantially. Other parties neither benefit nor lose in a statistically discernible way in this setting. The fact that the absolute size of the effects for CDU/CSU and SPD is considerably larger among the indifferent than in the models for the full sample (shown above in Table 22 provides support for Hypothesis $3 .{ }^{19}$ Finally, we test the same mechanism for voters of the Green Party and present results in the Appendix. Appendix Tables A.6 and A.7 do not suggest similar mechanisms on the left side of the political spectrum.

\section{Self-stated immigration position and AfD vote shares}

We argued that changes in vote choice under open lists should be most likely for voters who find the AfD and some other party similarly attractive for reasons other than their stance on immigration policy $\left(v_{j}=v_{k}\right)$. In this group, we should then see the largest shift in vote choice among those who are close to the midpoint of the immigration positions of their top-ranked parties. We next investigate whether this is actually the case.

Respondents stated their position on a 10-point immigration issue scale at the end of the survey ${ }^{20}$ Figure 6 shows treatment effects for individuals who are indifferent between AfD and some other party by respondents' self-stated position on immigration. Since immigration attitudes are substantially skewed towards the anti-immigration end of the scale (see also Table A.1 in the Appendix), this also applies to individuals who are indifferent between AfD and some other party. As the blue line in the lower panel suggests, approximately half of the indifferent respondents place themselves at a position of 7 or higher on the 10-point scale.

The bar plot in the upper panel of Figure6 shows the proportion of indifferent individ-

\footnotetext{
19 Table A.5 provides the corresponding estimates for the subsample of voters strictly preferring any party, be it the AfD or one of its competitors. We find no evidence that our treatments do affect respondents at conventional levels of statistical significance in this sample.

20

The measure is not biased by the treatment, see Table A.4 in the Appendix.
} 

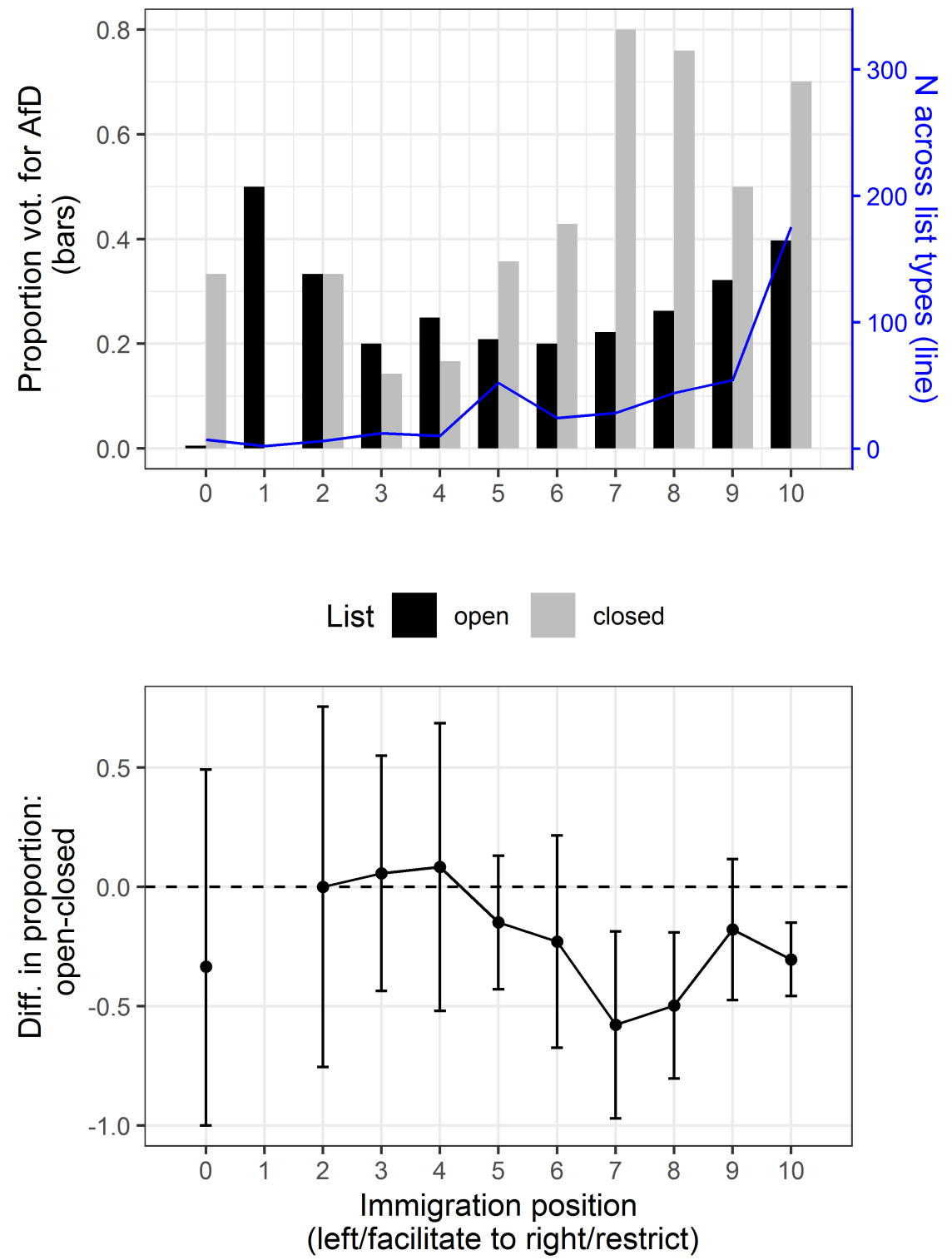

Figure 6: Treatment effects for individuals who are indifferent between AfD and some other party by immigration position. In the upper panel, bars show proportion of indifferent individuals voting for AfD by list type (there are no cases at scale point one in the closed condition; the observed zero proportion at scale point one in the open condition is displayed as .005); blue line represents total number of indifferent individuals at scale point. Lower panel displays differences in proportions between open and closed list with $95 \%$ confidence intervals $\left(\chi^{2}\right.$ test $)$ 
uals actually voting for AfD in the closed-list and in the open-list environment provided that they have received information about the immigration stance of candidates. The differences are striking. Respondents with a liberal to liberal-moderate attitude on immigration (say from 1 to 4), show similar odds of voting for the AfD, while respondents with moderate to restrictive attitudes are much more likely to cast an AfD vote in the closed-list as compared to the open-list treatment. Even more striking, the differences seems to be largest at the moderately restrictive positions, at 7 and 8 . While we have no information on where exactly on the dimension parties are perceived by respondents, we would expect neither respondents with views that are very restrictive nor respondents with liberal attitudes to be attracted to a heterogeneous candidate pool under open list. This is exactly what we find.

Are these differences substantial and significant? The lower panel of figure 6 shows differences in proportions of votes for AfD between open and closed lists with $95 \%$ confidence intervals (using a $\chi^{2}$ test). Indeed, we observe strong and substantial effects among those respondents who are more likely torn between the two parties. Among fairly immigration-skeptic individuals (7 and 8 on the x-axis), AfD support decreases by about 50 percentage points (indicated by the -0.5 point estimate for the ranges) as a function of the treatment.21

\section{Within-subject transitions from cohesive to incohesive parties}

Finally, we exploit the fact that we asked survey respondents twice which party to vote on, while varying the electoral system and keeping information levels constant. Given the within-subject comparison, these results hold any individual-level factors affecting voting behavior constant. In Figure 7 we show how respondents who opted for the the AfD (left

$\overline{21}$ We additionally conduct these analyses for the Green Party. Figure A.4 in the Appendix shows tentative evidence that similar effects apply to pro-immigration respondents who are indifferent between the Greens and some other party. However, the difference between the treatments fails to reach conventional levels of statistical significance. 
panel) and, respectively, the Greens (right panel) in round 1 (with a closed list setting) voted in round 2 (with an open list setting). Importantly, transitions to other parties differ substantially with our information treatment. As can be seen from the orange dots, without information treatment 94\% (90\%) of first-round AfD (Green) party supporters vote for the very same party in the second round. In contrast, when introducing candidate level information, only $72 \%(77 \%)$ of voters remain with their first-round choice. For the AfD, a substantial share of voters shifts to the CDU/CSU (10 percentage points), but also to the Left, FDP, and SPD (5-6 percentage points each). For the Green Party, we observe a shift of approximately 9 percentage points to the Left, and of 6 percentage points to each of CDU and SPD. Besides the last mentioned SPD shift, all these transition rates are significantly higher compared to the baseline group without information, and hence causally induced by our candidate-information treatment. In a second step, we exploit information on the individual candidates supported by these voters: As round 1 voters move to incohesive parties, they have to express support for either an immigrationskeptic or -friendly candidate. Round 1 AfD voters transitioning to an incohesive party with open lists in round 2 choose immigration-skeptic candidates in $87 \%$ (CI: [78\%, 93\%]) of cases. Round 1 Green voters transitioning to an incohesive party with open lists in round 2 choose immigration-friendly candidates in $54 \%$ (CI: [40\%, 68\%]) of cases. We can compare these shares to the support of immigration-sceptic (friendly) candidates by all other voters for incohesive parties in round 2. There, $69 \%$ (CI: [66\%, 72\%]) vote for immigration sceptic, $31 \%$ (CI: $[28 \%, 34 \%])$ for immigration friendly candidates, which is a significant difference to the voters transitioning from cohesive parties.

In summary, the individual-level evidence clearly supports the argument that closed list voters of cohesive parties switch to heterogenous parties in an open-list setting. While opting for a new party, they predominantly keep supporting candidates in line with the policy position of the cohesive party they formerly supported. 


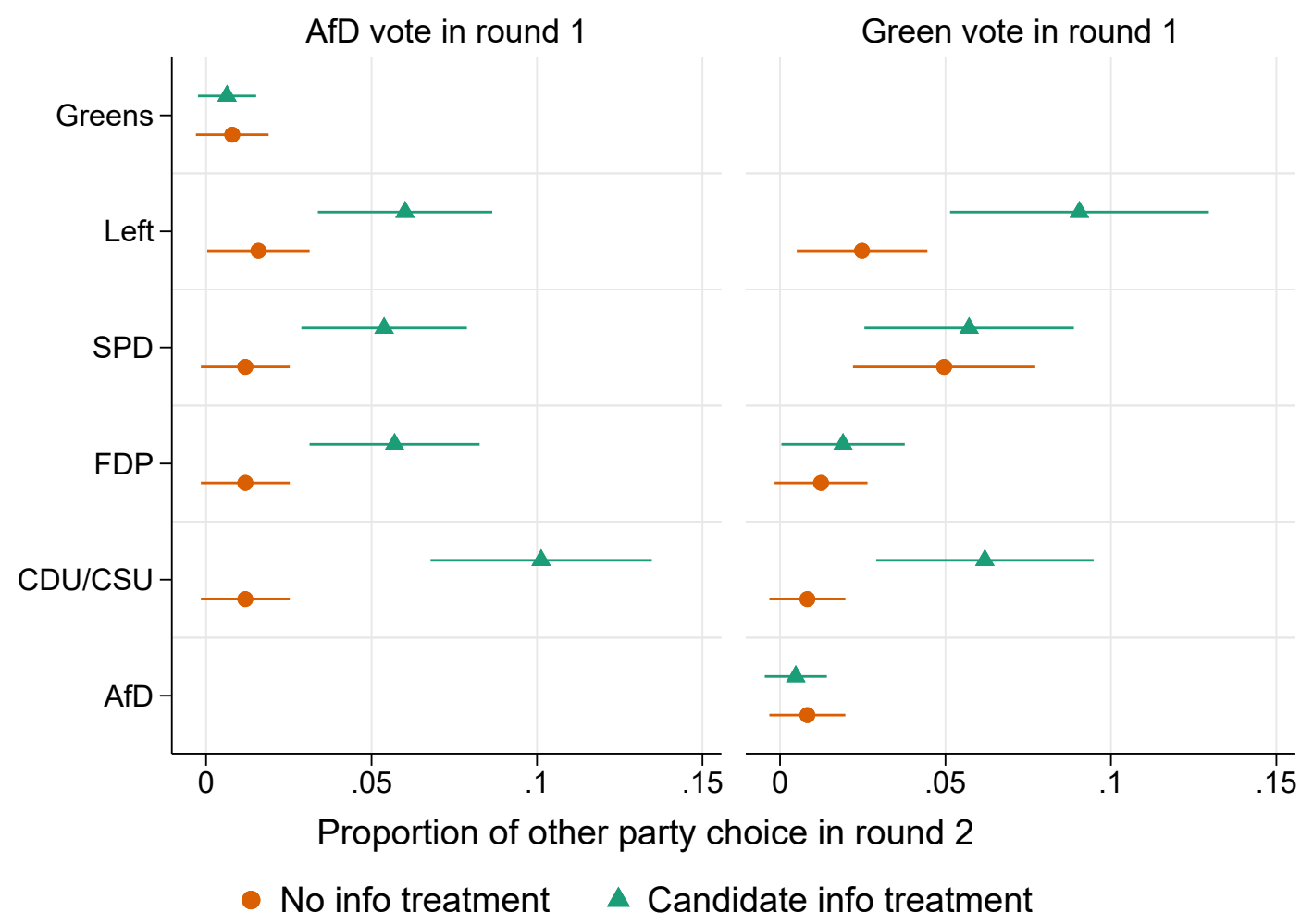

Figure 7: Within-respondent analysis for voters of cohesive parties (AfD, left panel; Greens, right panel) in round 1 by information treatment (no: orange dots; yes: green triangles) when voting in a closed-list setting first, and an openlist setting second. Coefficients show the share of cohesive-party supporters in round 1 (with closed lists) that transition to another party in round 2 (with open lists).

\section{Conclusion}

Our paper makes two contributions to the analysis of spatial voting under open-list compared to closed-list PR. First, we introduced a formal model showing how voters consider party-level valence and spatial proximity, while allowing candidate choice to affect the future party position. From this follows the prediction that especially citizens who are close to indifferent between their two most preferred parties may cast their vote differently under closed-list and open-list rules; under open-list ballots, they may pick 
a candidate from a heterogeneous mainstream party rather than a candidate from the unified single-issue challenger. Also, the voters most susceptible to change their choice should have ideal points in the middle between the internally divided and cohesive parties.

Second, we find strong empirical support for these arguments in our experiment: With open lists, we observe an aggregate vote shift from the immigration-skeptic AfD to the more moderate CDU/CSU. In line with our hypotheses, this move is particularly pronounced among voters close to indifferent between the two parties and for voters who hold moderately immigration-skeptic views. The within-subject analysis confirms these patterns and shows that vote switching goes along with supporting candidates who share positions of the deserted homogenous party. We do not find that an emphasis frame on the workings of the open-list electoral system affects behavior under open lists differently, possibly indicating that voters have a sound understanding of the systems' consequences. A treatment on the opposing end of the policy space (presenting the Green Party with a unified pro-immigration position) produced mixed results. While switching occurred at the individual-level over the two rounds, we did not find a statistically significant effect on aggregate vote shares. This indicates that a substantial amount of indifferent voters needs to be placed between cohesive and heterogenous party for ballot type to make a difference. Notably, the mere provision of information on candidates' immigration positions increased the vote share of the populist AfD, especially among citizens indifferent between CDU/CSU and AfD. A plausible explanation is that the information-only treatment acted as a salience shock that increased the weight of the immigration dimension in vote choice. With closed lists, voters are attracted to the party offering a unified position on the salient dimension; under open lists, this shift is reversed, since voters can select candidates representing such views within the party they prefer on other grounds.

There are several worthwhile avenues for further research. For example, the formal model could allow for individual voters having varying perceptions of candidate influence 
on the party position. It is possible that these beliefs systematically vary with their own ideal point or that citizens consider which candidates within a party other voters will support. In empirical terms, it would be interesting to examine whether post-electoral party positioning in open-list systems reflects the views of politicians with strong personal vote results. This is plausible, since other work has already shown beneficial effects of individual electoral performance on intra-party careers (André et al. 2017; Folke, Persson and Rickne 2016).

The findings have practical implications for institutional design. Closed-list PR is an electoral system offering voters only limited options to express their preferences. Granting voters more opportunities to choose can be conceived as desirable per se, and the trend towards more "personalized" electoral systems, as observed in Europe over recent decades (Renwick and Pilet 2016), may continue. With societies becoming more differentiated, issues cutting across traditional party lines are likely to appear more frequently. In an open-list system, parties can react by offering a range of policy options on such issues through different candidates, whereas in a closed-list system this can happen at best indirectly. List type will have an impact on party choice, especially in contexts where valence considerations and policy positions leave many voters indifferent, for example, between a heterogeneous mainstream party and a homogeneous challenger.

Our study also informs the more specific debate on how mainstream parties may deal with anti-immigration, populist challenges (Dahlström and Sundell 2012). The literature discusses whether mainstream parties can limit the success of populist parties by becoming tougher on immigration (Bale 2003; ?), or whether this facilitates populist radical right parties' success this puts additional emphasis on immigration Arzheimer and Carter 2006). Our findings suggest that mainstream parties can limit the success of populist parties by providing heterogeneous positions on a key dimension for populist radical right parties, immigration - if the electoral rules permit citizens to support candidates 
with immigration-skeptic positions.

\section{References}

Abou-Chadi, Tarik and Marc Helbling. 2018. "How immigration reforms affect voting behavior." Political Studies 66(3):687-717.

André, Audrey, Sam Depauw and Matthew S Shugart. 2014. The Effect of Electoral Institutions on Legislative Behavior. In The Oxford Handbook of Legislative Studies, ed. Shane Martin, Thomas Saalfeld and Kaare Strøm. Oxford: Oxford University Press.

André, Audrey, Sam Depauw, Matthew S Shugart and Roman Chytilek. 2017. "Party nomination strategies in flexible-list systems: Do preference votes matter?" Party Politics 23(5):589-600.

Ansolabehere, Stephen and James M. Snyder Jr. 2000. "Valence Politics and Equilibrium in Spatial Election Models." Public Choice 103(3-4):327-336.

Arzheimer, Kai and Elisabeth Carter. 2006. "Political Opportunity Structures and RightWing Extremist Party Success." European Journal of Political Research 45(3):419-443.

Bale, Tim. 2003. "Cinderella and Her Ugly Sisters: The Mainstream and Extreme Right in Europe's Bipolarising Party Systems." West European Politics 26(3):67-90.

Blumenau, Jack, Andrew C. Eggers, Dominik Hangartner and Simon Hix. 2017. "Open/Closed List and Party Choice: Experimental Evidence from the UK." British Journal of Political Science 47(04):809-827.

Bowler, Shaun, David M. Farrell and Richard S. Katz. 1999. Party cohesion, party discipline, and parliaments. In Party Discipline and Parliamentary Government, ed. Shaun Bowler, David M. Farrell and Richard S. Katz. Columbus: Ohio State University Press pp. 3-22.

Carey, John M. 2009. Legislative voting and accountability. Cambridge: Cambridge 
University Press.

Carey, John M. and Matthew Søberg Shugart. 1995. "Incentives to cultivate a personal vote. A rank-ordering of electoral formulas." Electoral Studies 14(4):417-439.

Carroll, Royce and Monika Nalepa. 2020. "The personal vote and party cohesion: Modeling the effects of electoral rules on intraparty politics." Journal of Theoretical Politics $32(1): 36-69$

Colomer, Josep M. 2011. Personal representation. The neglected dimension of electoral systems. Colchester: ECPR Press.

Crisp, Brian F., Maria C. Escobar-Lemmon, Bradford S. Jones, Mark P. Jones and Michelle M. Taylor-Robinson. 2004. "Vote-Seeking Incentives and Legislative Representation in Six Presidential Democracies." The Journal of Politics 66(3):823-846.

Dahlström, Carl and Anders Sundell. 2012. "A Losing Gamble. How Mainstream Parties Facilitate Anti-Immigrant Party Success." Electoral Studies 31(2):353-363.

Druckman, James N. 2001. "The Implications of Framing Effects for Citizen Competence." Political Behavior 23(3):225-256.

Folke, Olle, Torsten Persson and Johanna Rickne. 2016. "The Primary Effect: Preference Votes and Political Promotions." American Political Science Review 110(3):559-578.

Franchino, Fabio and Marco Mainenti. 2013. "Electoral Institutions and Distributive Policies in Parliamentary Systems: An Application to State Aid Measures in EU Countries." West European Politics 36(3):498-520.

Groseclose, Tim. 2001. "A Model of Candidate Location When One Candidate Has a Valence Advantage." American Journal of Political Science 45(4):862.

Krehbiel, Keith. 1993. "Where's the party?" British Journal of Political Science 23(2):235-266.

Poole, Keith, Jeffrey Lewis, Howard Rosenthal, James Lo and Royce Carroll. 2016. "Recovering a Basic Space from Issue Scales in R." Journal of Statistical Software 69(7):1- 
21.

Renwick, Alan and Jean-Benoit Pilet. 2016. Faces on the ballot. The personalization of electoral systems in Europe. Oxford: Oxford University Press.

Roßteutscher, Sigrid, Rüdiger Schmitt-Beck, Harald Schoen, Bernhard Weßels, Christof Wolf, Aiko Wagner, Reinhold Melcher and Heiko Giebler. 2019. "Post-election Cross Section (GLES 2017)Nachwahl-Querschnitt (GLES 2017).”.

Schofield, Norman and Itai Sened. 2006. Multiparty democracy: Elections and legislative politics. Cambridge: Cambridge University Press.

Shugart, Matthew S. 2013. Why ballot structure matters. In Political Science, Electoral Rules, and Democratic Governance. Report of the Task Force on Electoral Rules and Democratic Governance, ed. Mala Htun and G. Bingham Jr. Powell. Washington: American Political Science Association pp. 38-45.

Spiegel. 2016. "Grünen-Spitze Distanziert Sich von Boris Palmer." https://www.spiegel.de/politik/deutschland/boris-palmer-gruene-cem-oezdemirund-simone-peters-distanzieren-sich-a-1077322.html.

Stokes, Donald E. 1963. "Spatial models of party competition." American political science review 57(2):368-377.

Stokes, Donald E. 1992. Valence Politics. In Electoral Politics, ed. Dennis Kavanagh. Clarendon Press pp. 161-164.

Stone, Walter J. 2017. Candidates and voters: Ideology, valence, and representation in US elections. Cambridge University Press.

Strøm, Kaare, Wolfgang C. Müller and Torbjörn Bergman. 2006. Delegation and accountability in parliamentary democracies. Oxford: Oxford University Press.

Walgrave, Stefaan and Knut De Swert. 2004. "The making of the (issues of the) Vlaams Blok." Political Communication 21(4):479-500. 


\section{Online Appendix}

\section{Descriptive Statistics}

This Appendix Section presents descriptive statistics. Table A.1 displays mean, standard deviation and range for all variables used in the balance tests (Tables A.2, A.3, A.4) and the analyses.

Figure A.1 displays the distribution of immigration attitudes amongst survey respondents. The variable's mean (6.4 on a scale from 0 to 10; see Table A.1) already suggests that the average respondent in our sample is immigration-sceptic. Figure A.1 further confirms this and indicates that the mode is the most immigration-sceptic category. In other words, more than 1500 out of 6600 respondents are extremely immigration-sceptic.

\begin{tabular}{llccccc}
\hline Variable & Scale/Level & $\mathrm{N}$ & Mean & SD & Min & Max \\
\hline Age & & 6600 & 47.6 & 15.7 & 19 & 95 \\
Education & Lo & 6600 & 0.36 & 0.48 & 0 & 1 \\
Education & $\mathrm{Me}$ & 6600 & 0.31 & 0.46 & 0 & 1 \\
Education & $\mathrm{Hi}$ & 6600 & 0.33 & 0.47 & 0 & 1 \\
Employment & Employed & 6600 & 0.56 & 0.50 & 0 & 1 \\
Income & 15 levels & 6600 & 7.35 & 3.32 & 1 & 15 \\
Gender & Female & 6600 & 0.50 & 0.50 & 0 & 1 \\
Political Interest & 5 levels & 6600 & 3.33 & 1.06 & 1 & 5 \\
Region & West & 6600 & 0.63 & 0.48 & 0 & 1 \\
Region & East & 6600 & 0.22 & 0.41 & 0 & 1 \\
Region & Bavaria & 6600 & 0.15 & 0.35 & 0 & 1 \\
Immigration & 11 levels & 6600 & 6.44 & 2.98 & 0 & 10 \\
\hline
\end{tabular}

Table A.1: Descriptive Statistics

Finally, by analogy with Figure 4, Figure A.2 reports the share of respondents indifferent between Green party and Social Democratic Party. While a substantial share of respondents are indifferent between both parties across all immigration positions (approximately $20 \%$ ), the distribution peaks at the immigration-friendly end of the scale. 


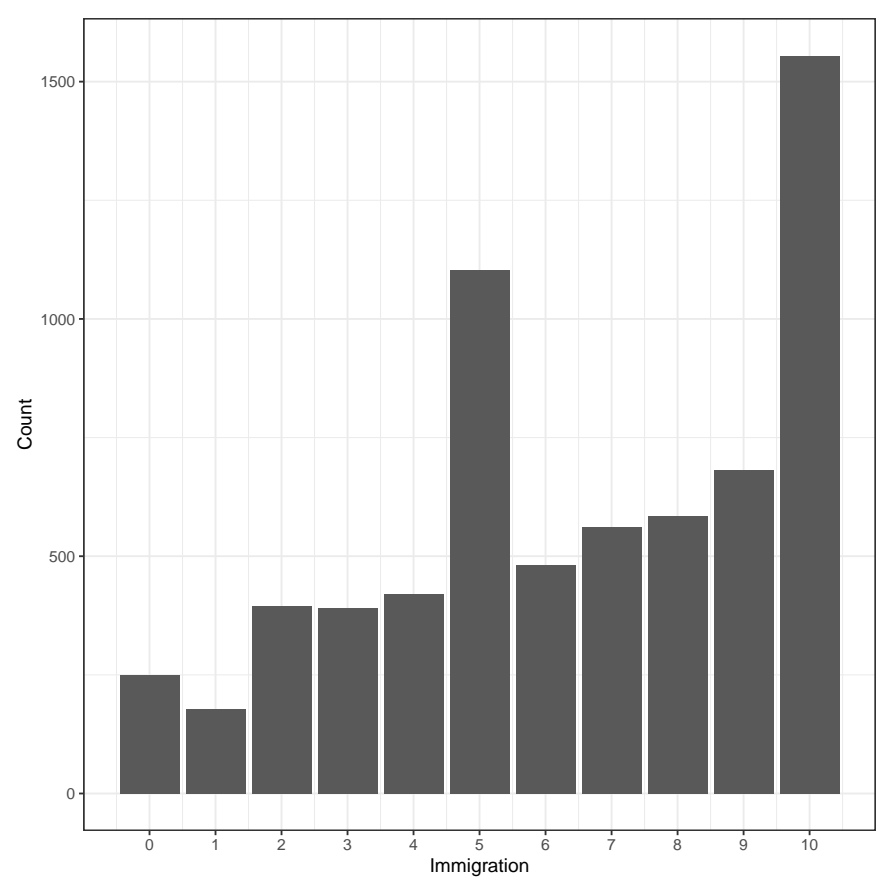

Figure A.1: Distribution of immigration attitudes

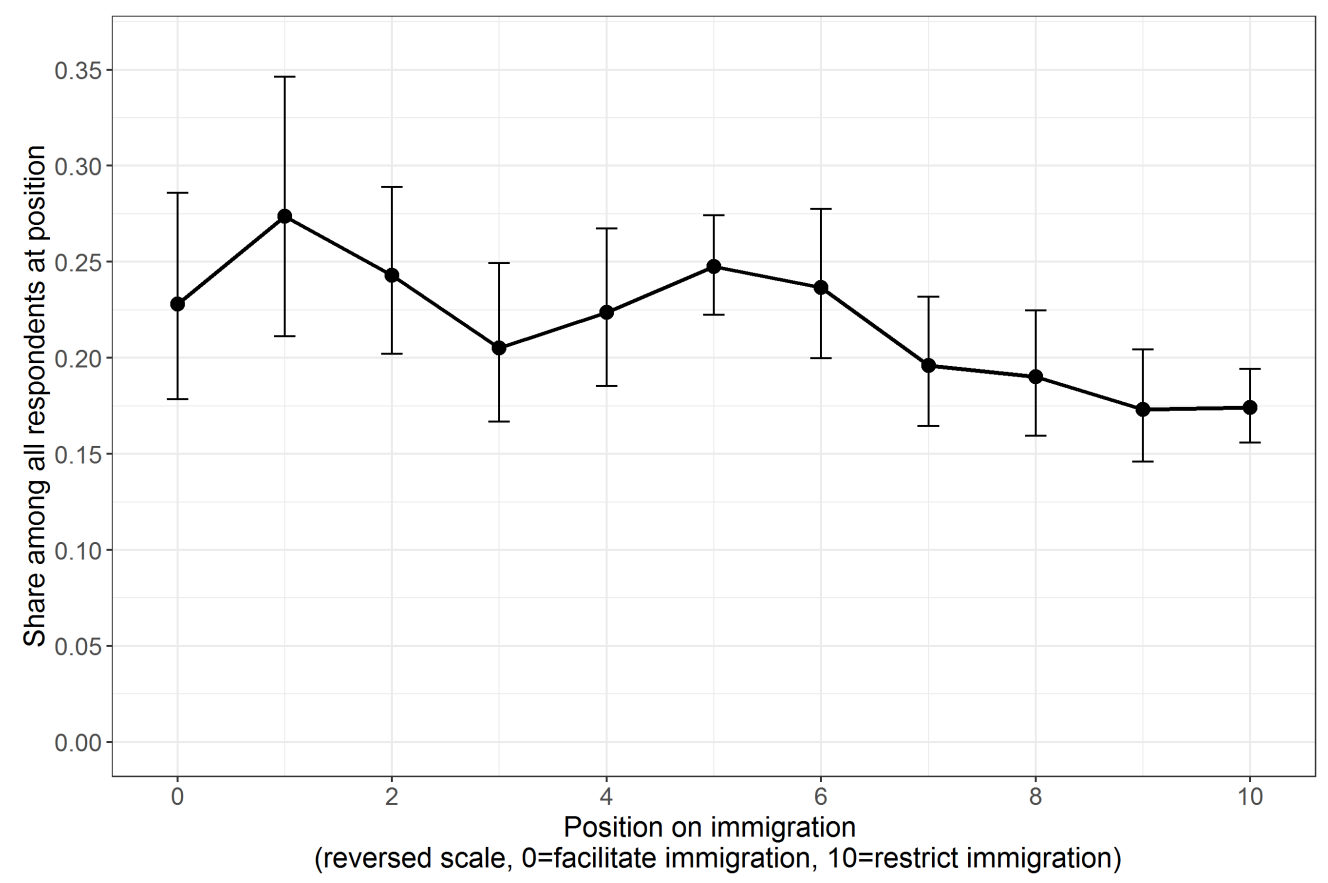

Figure A.2: Share of respondents indifferent between SPD and Green Party, by selfreported immigration position. 


\section{Additional Information - Experiment}

This Appendix Sections assesses whether the randomization process produced comparable distributions in the differing treatment arms for observable covariates. We conducted several balance tests. Most importantly, Figure A.3 shows whether the p-values from our balance tests (see Tables A.2, A.3, and A.4 follow the expected uniform distribution. Each point refers to the p-value of one dependent variable. Overall, the distribution of p-values follows a uniform distribution. This suggests that the random assignment to our treatment worked appropriately.

\section{Balance tests}

\begin{tabular}{lcccccc}
\hline & Age & Gender & Education & Employment & Income & Region = East \\
\hline (Intercept) & $48.08^{* * *}$ & $0.51^{* * *}$ & $0.36^{* * *}$ & $0.55^{* * *}$ & $7.45^{* * *}$ & $0.23^{* * *}$ \\
& $(0.43)$ & $(0.01)$ & $(0.01)$ & $(0.01)$ & $(0.10)$ & $(0.01)$ \\
Open List & -0.01 & 0.00 & -0.01 & 0.01 & -0.08 & -0.01 \\
& $(0.61)$ & $(0.02)$ & $(0.02)$ & $(0.02)$ & $(0.13)$ & $(0.02)$ \\
Information & $-1.45^{*}$ & -0.00 & -0.01 & 0.01 & -0.22 & -0.00 \\
& $(0.61)$ & $(0.02)$ & $(0.02)$ & $(0.02)$ & $(0.13)$ & $(0.02)$ \\
Open List x Information & 1.17 & -0.02 & 0.00 & -0.00 & 0.19 & -0.01 \\
& $(0.86)$ & $(0.03)$ & $(0.03)$ & $(0.03)$ & $(0.19)$ & $(0.02)$ \\
\hline $\mathrm{R}^{2}$ & 0.00 & 0.00 & 0.00 & 0.00 & 0.00 & 0.00 \\
Adj. R ${ }^{2}$ & 0.00 & -0.00 & -0.00 & -0.00 & -0.00 & -0.00 \\
Num. obs. & 5281 & 5281 & 5281 & 5281 & 4861 & 5281 \\
RMSE & 15.67 & 0.50 & 0.48 & 0.50 & 3.31 & 0.42 \\
\hline
\end{tabular}

${ }^{* * *} p<0.001,{ }^{* *} p<0.01,{ }^{*} p<0.05$

Table A.2: Balance test: Demographics 


\begin{tabular}{lcccccc}
\hline & CDU/CSU & SPD & AfD & Greens & FDP & Left \\
\hline Intercept) & $4.17^{* * *}$ & $4.22^{* * *}$ & $2.24^{* * *}$ & $4.19^{* * *}$ & $3.46^{* * *}$ & $3.48^{* * *}$ \\
& $(0.08)$ & $(0.08)$ & $(0.09)$ & $(0.08)$ & $(0.07)$ & $(0.08)$ \\
Open List & -0.15 & $-0.23^{*}$ & -0.08 & -0.08 & -0.13 & -0.12 \\
& $(0.11)$ & $(0.11)$ & $(0.12)$ & $(0.12)$ & $(0.10)$ & $(0.11)$ \\
Information & -0.01 & -0.00 & -0.13 & -0.04 & -0.02 & -0.05 \\
& $(0.11)$ & $(0.11)$ & $(0.12)$ & $(0.12)$ & $(0.10)$ & $(0.11)$ \\
Open List x Information & 0.13 & 0.19 & 0.26 & 0.02 & 0.16 & 0.19 \\
& $(0.16)$ & $(0.15)$ & $(0.18)$ & $(0.17)$ & $(0.14)$ & $(0.16)$ \\
\hline $\mathrm{R}^{2}$ & 0.00 & 0.00 & 0.00 & 0.00 & 0.00 & 0.00 \\
Adj. R & -0.00 & 0.00 & -0.00 & -0.00 & -0.00 & -0.00 \\
Num. obs. & 5281 & 5281 & 5281 & 5281 & 5281 & 5281 \\
RMSE & 2.93 & 2.76 & 3.18 & 3.04 & 2.56 & 2.92 \\
\hline
\end{tabular}

${ }^{* * *} p<0.001,{ }^{* *} p<0.01,{ }^{*} p<0.05$

Table A.3: Balance test: Scalometer

\begin{tabular}{lccc}
\hline & Immigration & Left-Right Self-Placement & Political Interest \\
\hline Intercept) & $6.36^{* * *}$ & $4.63^{* * *}$ & $3.31^{* * *}$ \\
Open List & $(0.08)$ & $(0.06)$ & $(0.03)$ \\
& 0.03 & -0.01 & 0.04 \\
Information & $(0.12)$ & $(0.08)$ & $(0.04)$ \\
& 0.17 & -0.02 & -0.02 \\
Open List x Information & $(0.12)$ & $(0.08)$ & $(0.04)$ \\
& -0.12 & -0.01 & 0.05 \\
$\mathrm{R}^{2}$ & $(0.16)$ & $(0.12)$ & $(0.06)$ \\
Adj. R & 0.00 & 0.00 & 0.00 \\
Num. obs. & -0.00 & -0.00 & 0.00 \\
RMSE & 5281 & 5281 & 5281 \\
\hline
\end{tabular}

${ }^{* * *} p<0.001,{ }^{* *} p<0.01,{ }^{*} p<0.05$

Table A.4: Balance test: Political Variables 


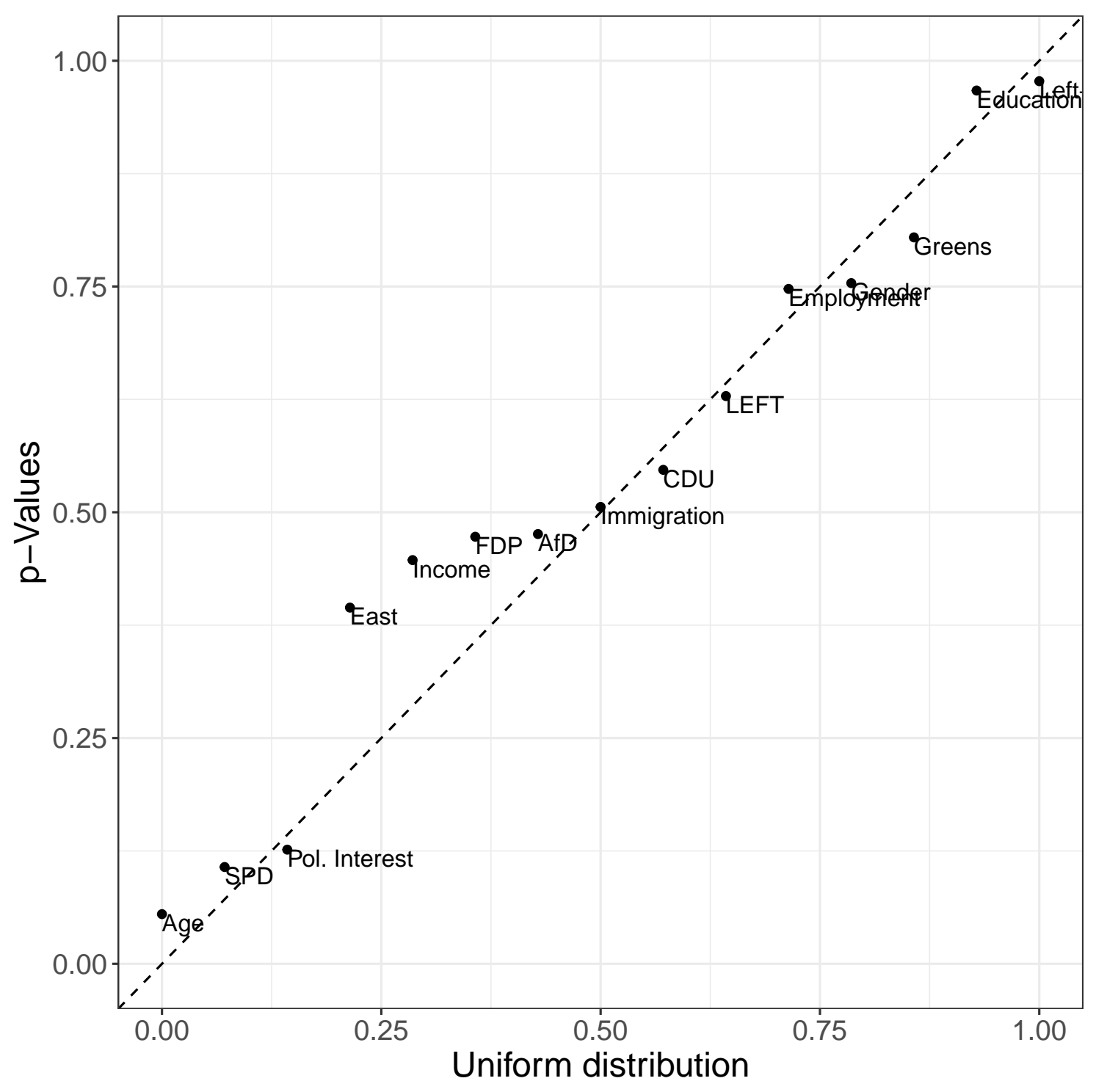

Figure A.3: Quantile-quantile plot of empirical distribution of p-values against uniform. The labels of each point refer to the dependent variable of the subsequent analysis. 


\section{Indifferent voters}

In this section, we present additional information accompagning our analyses of indifferent AfD voters (see the respective section in the main text and particularly Table 4).

Table A.5 shows the results for all voters who are not indifferent between the AfD and any other party. These are voters who only support the AfD or support any other party most and do not support the AfD to a similar extent (AfD rating outside 1 point on a 10-point scale). There is no indication that the aggregate vote share of the AfD is systematically affected by the treatments for this subgroup. This is in line with our argument, since we expect that it is in particular indifferent voters who are affected by the combination of information and list type.

\begin{tabular}{lcccccc}
\hline & Greens & Left & SPD & FDP & CDU/CSU & AfD \\
\hline Intercept & $0.21^{* * *}$ & $0.14^{* * *}$ & $0.18^{* * *}$ & $0.08^{* * *}$ & $0.24^{* * *}$ & $0.15^{* * *}$ \\
& $(0.01)$ & $(0.01)$ & $(0.01)$ & $(0.01)$ & $(0.01)$ & $(0.01)$ \\
Open List & -0.02 & 0.01 & 0.02 & 0.01 & -0.02 & -0.00 \\
& $(0.02)$ & $(0.02)$ & $(0.02)$ & $(0.01)$ & $(0.02)$ & $(0.02)$ \\
Information & -0.02 & -0.00 & 0.02 & 0.00 & -0.02 & 0.02 \\
& $(0.02)$ & $(0.02)$ & $(0.02)$ & $(0.01)$ & $(0.02)$ & $(0.02)$ \\
Open List x Info. & -0.03 & 0.02 & -0.02 & -0.00 & 0.05 & -0.01 \\
& $(0.02)$ & $(0.02)$ & $(0.02)$ & $(0.02)$ & $(0.03)$ & $(0.02)$ \\
\hline Num. obs. & 4434 & 4434 & 4434 & 4434 & 4434 & 4434 \\
\hline
\end{tabular}

Table A.5: Subgroup effects of ballot type and information for voters not indifferent between the AfD and any other party, while ranking these parties highest. Coefficients estimated from a linear regression of ballot type (open vs. closed list), provision of information (yes vs. no), and its interaction on party choice (binary indicator whether party in model header is voted for) for this subgroup. Entries are unstandardized regression coefficients from linear regression models. Standard errors in parentheses. ${ }^{*} p<0.05,{ }^{* *} p<0.01$, ${ }^{* * *} p<0.001$.

In parallel to the previous discussion, Tables A.6 and A.7 summarise treatment effects for the Green Party for the subgroups of voters (not) indifferent between Green party and any other party (while ranking the Green party and any other party highest). By- 
and-large, the results suggest that our treatments did not move aggregated vote choice for the Green Party. Starting with Table A.6, voters who rate the Green Party highest, but any other party with a 1-point-range, are not systematically moved by our treatment conditions. Note that treatment effects persist for AfD and CDU/CSU vote shares. Most likely, this effect stems from voters who rank all parties similarly, e.g. rank them all with a zero or five on the party ranking scale (range 0 to 10). In contrast, voters other than Green-indifferent voters, i.e. other voters with a clear party preference, do not react to our experimental stimuli (see Table A.7).

In other words, the data is not consistent with a similar effect of our treatments on the left of the party spectrum.

\begin{tabular}{lcccccc}
\hline & Greens & Left & SPD & FDP & CDU/CSU & AfD \\
\hline (Intercept) & $0.28^{* * *}$ & $0.14^{* * *}$ & $0.23^{* * *}$ & $0.08^{* * *}$ & $0.20^{* * *}$ & $0.07^{* * *}$ \\
& $(0.02)$ & $(0.02)$ & $(0.02)$ & $(0.01)$ & $(0.02)$ & $(0.01)$ \\
Open List & -0.01 & -0.00 & 0.02 & 0.02 & -0.03 & -0.00 \\
& $(0.03)$ & $(0.02)$ & $(0.03)$ & $(0.02)$ & $(0.03)$ & $(0.02)$ \\
Information & -0.03 & -0.02 & 0.01 & 0.02 & -0.03 & $0.06^{* *}$ \\
& $(0.03)$ & $(0.02)$ & $(0.03)$ & $(0.02)$ & $(0.03)$ & $(0.02)$ \\
Open List x Info. & -0.01 & 0.03 & 0.00 & -0.03 & $0.08^{*}$ & $-0.08^{* *}$ \\
& $(0.04)$ & $(0.03)$ & $(0.04)$ & $(0.03)$ & $(0.04)$ & $(0.03)$ \\
\hline Num. obs. & 1812 & 1812 & 1812 & 1812 & 1812 & 1812 \\
\hline
\end{tabular}

Table A.6: Subgroup effects of ballot type and information for voters indifferent between the Greens and any other party, while ranking these parties highest. Coefficients estimated from a linear regression of ballot type (open vs. closed list), provision of information (yes vs. no), and its interaction on party choice (binary indicator whether party in model header is voted for) for this subgroup. Entries are unstandardized regression coefficients from linear regression models. Standard errors in parentheses. ${ }^{*} p<0.05,{ }^{* *} p<0.01$, ${ }^{* * *} p<0.001$. 


\begin{tabular}{lcccccc}
\hline & Greens & Left & SPD & FDP & CDU/CSU & AfD \\
\hline Intercept) & $0.13^{* * *}$ & $0.13^{* * *}$ & $0.15^{* * *}$ & $0.09^{* * *}$ & $0.24^{* * *}$ & $0.26^{* * *}$ \\
& $(0.01)$ & $(0.01)$ & $(0.01)$ & $(0.01)$ & $(0.01)$ & $(0.01)$ \\
Open List & -0.01 & 0.02 & 0.02 & 0.01 & -0.01 & -0.02 \\
& $(0.02)$ & $(0.02)$ & $(0.02)$ & $(0.01)$ & $(0.02)$ & $(0.02)$ \\
Information & -0.02 & 0.00 & 0.01 & -0.01 & -0.03 & 0.04 \\
& $(0.02)$ & $(0.02)$ & $(0.02)$ & $(0.01)$ & $(0.02)$ & $(0.02)$ \\
Open List x Info. & -0.03 & 0.00 & -0.01 & 0.02 & 0.05 & -0.04 \\
& $(0.02)$ & $(0.02)$ & $(0.03)$ & $(0.02)$ & $(0.03)$ & $(0.03)$ \\
\hline Num. obs. & 3469 & 3469 & 3469 & 3469 & 3469 & 3469 \\
\hline
\end{tabular}

Table A.7: Subgroup effects of ballot type and information for voters not indifferent between the Greens and any other party, while ranking these parties highest. Coefficients estimated from a linear regression of ballot type (open vs. closed list), provision of information (yes vs. no), and its interaction on party choice (binary indicator whether party in model header is voted for) for this subgroup. Entries are unstandardized regression coefficients from linear regression models. Standard errors in parentheses. ${ }^{*} p<0.05,{ }^{* *} p<0.01$, ${ }^{* * *} p<0.001$.

\section{Self-stated immigration position and Green vote shares}

Figure A.4 presents the corresponding results to Figure 6 in the main text for the Green party. The blue line in the upper panel shows the number of respondents indifferent between the Greens and any other party across their self-placement on the immigration scale, given information. The bars demonstrate that the majority of Green party voters are placed towards the immigration-friendly (left) side of the immigration scale. The lower panel depicts the change in proportions of the Green Party vote share between open and closed lists. We see some tentative evidence for list type at the highly immigration-friendly end of the scale, although the difference-in-proportions test fail to reach conventional levels of significance. 


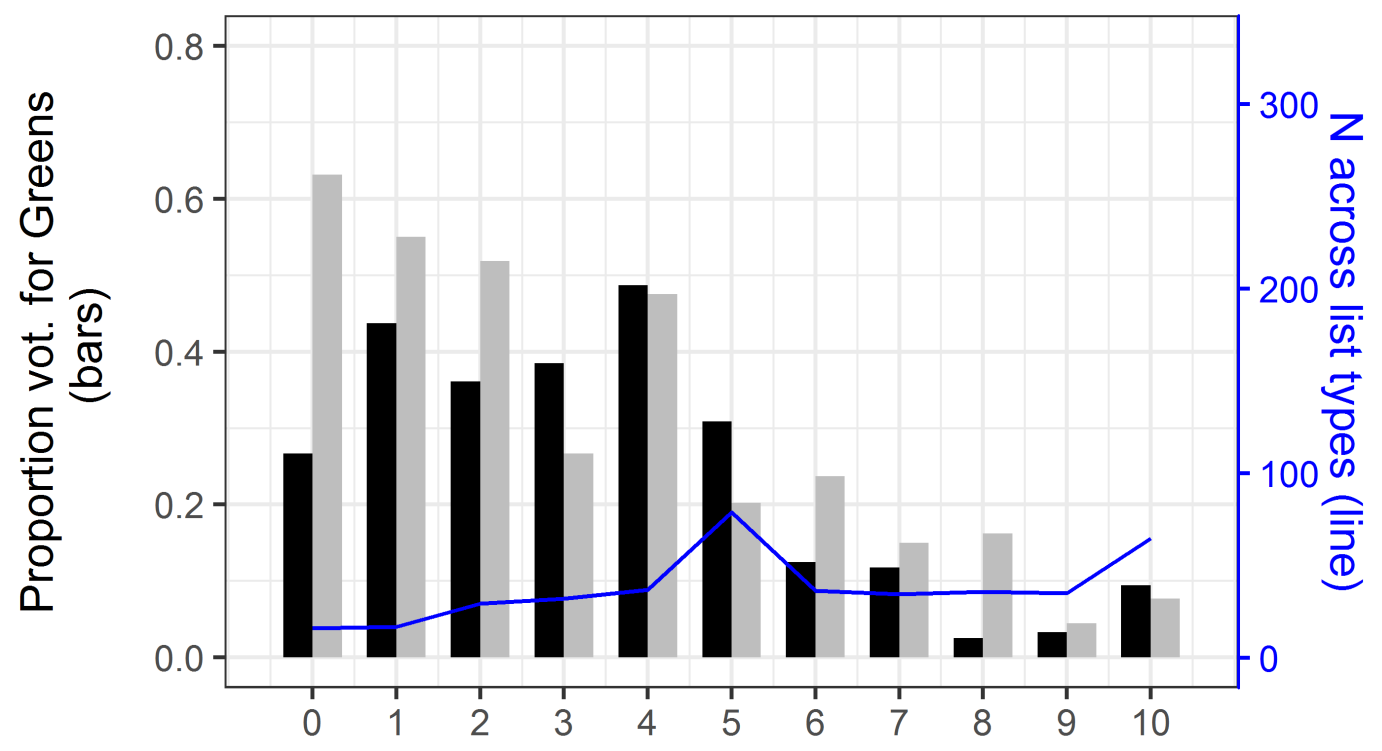

List open closed

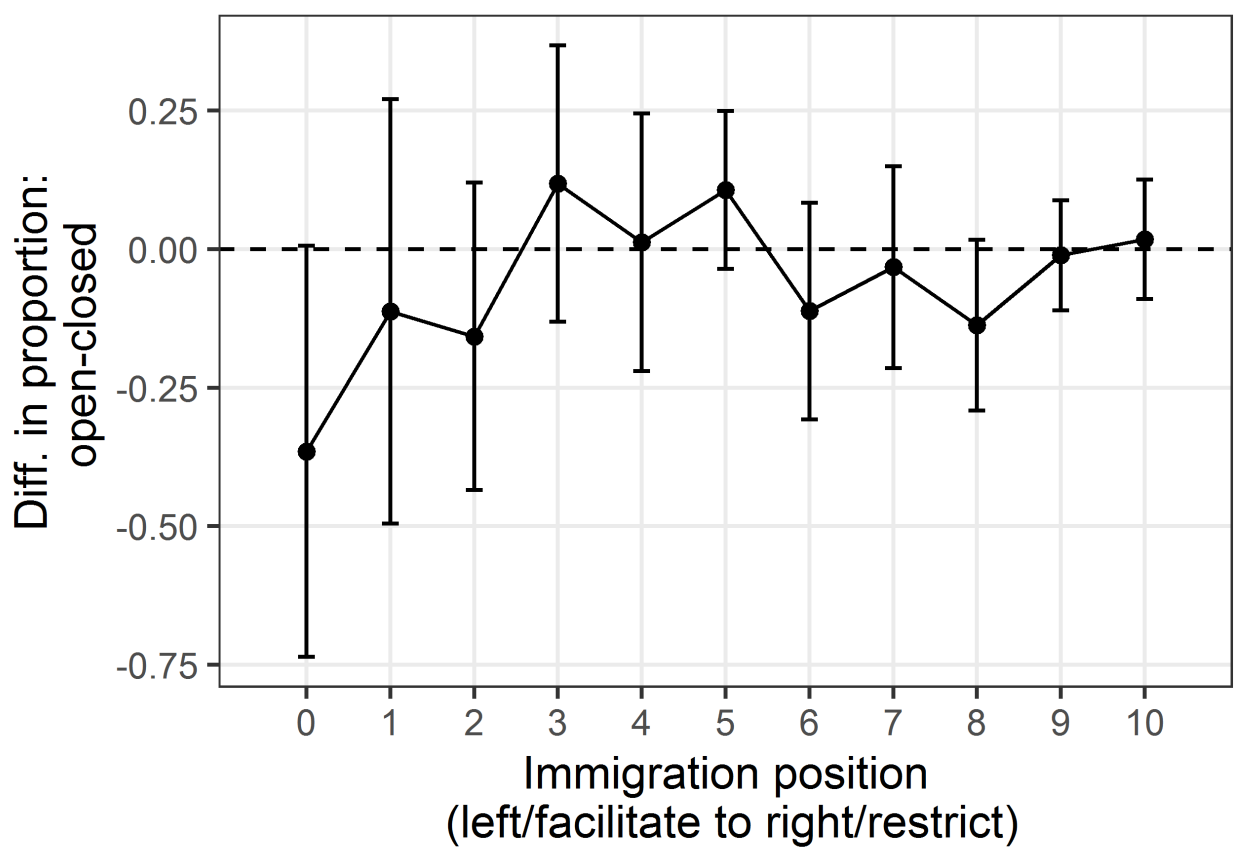

Figure A.4: Treatment effects for individuals who are indifferent between Greens and some other party by immigration position. In the upper panel, bars show proportion of indifferent individuals voting for Greens by list type; blue line represents total number of indifferent individuals at scale point. Lower panel displays differences in proportions between open and closed list with $95 \%$ confidence intervals ( $\chi^{2}$ test) 


\section{Regression analysis using a multinomial model}

This Appendix Section presents robustness tests for our main results. In particular, we reran the analysis presented in Table 2 using multinomial logistic regression. Voting for the AfD serves as the reference category. The positive and significant coefficent of the interaction term for the CDU/CSU suggests that, given information, particularly the CDU/CSU profits from the open list ballot type at the expense of the AfD. 


\begin{tabular}{lccccc}
\hline & CDU/CSU & Left & FDP & Greens & SPD \\
\hline Intercept) & 0.16 & $-0.35^{* * *}$ & $-0.79^{* * *}$ & -0.04 & -0.08 \\
& $(0.09)$ & $(0.10)$ & $(0.11)$ & $(0.09)$ & $(0.09)$ \\
Open List & -0.02 & 0.15 & 0.18 & -0.01 & 0.15 \\
& $(0.12)$ & $(0.14)$ & $(0.16)$ & $(0.13)$ & $(0.13)$ \\
Information & $-0.35^{* *}$ & $-0.27^{*}$ & -0.22 & $-0.36^{* *}$ & -0.16 \\
& $(0.12)$ & $(0.14)$ & $(0.16)$ & $(0.13)$ & $(0.12)$ \\
Open List x Information & $0.51^{* *}$ & 0.34 & 0.26 & 0.08 & 0.23 \\
& $(0.17)$ & $(0.19)$ & $(0.22)$ & $(0.19)$ & $(0.18)$ \\
\hline AIC & 18569.76 & 18569.76 & 18569.76 & 18569.76 & 18569.76 \\
BIC & 18701.19 & 18701.19 & 18701.19 & 18701.19 & 18701.19 \\
Log Likelihood & -9264.88 & -9264.88 & -9264.88 & -9264.88 & -9264.88 \\
Deviance & 18529.76 & 18529.76 & 18529.76 & 18529.76 & 18529.76 \\
Num. obs. & 5281 & 5281 & 5281 & 5281 & 5281 \\
\hline
\end{tabular}

${ }^{* * *} p<0.001,{ }^{* *} p<0.01,{ }^{*} p<0.05$

Table A.8: Effects of ballot type and information. Coefficients estimated from a multinomial logistic regression of ballot type (open vs. closed list), provision of information (yes vs. no) and its interaction on party choice (binary indicator whether party in model header is voted for). Entries stem from multinomial logistic regression. Standard errors in parentheses. ${ }^{*} p<0.05,{ }^{* *} p<0.01$, ${ }^{* * *} p<0.001$. 